\title{
Article \\ Similarities and Contrasts in Stationary Striations of Surface Tracers in Pacific Eastern Boundary Upwelling Systems
}

\author{
Ali Belmadani ${ }^{1,}{ }^{*}$, Pierre-Amaël Auger ${ }^{2}$, Katherine Gomez $^{3}$, Nikolai Maximenko ${ }^{4}$ and Sophie Cravatte ${ }^{5}$ \\ 1 Department of Geophysics, University of Concepcion, Concepcion, Chile; ali.belmadani@meteo.fr \\ 2 Department of Geophysics, University of Concepcion, Concepcion, Chile; Millennium Institute of \\ Oceanography (IMO), University of Concepcion, Concepcion, Chile; and Univ. Brest, CNRS, IRD, Ifremer, \\ Laboratoire d'Océanographie Physique et Spatiale (LOPS), IUEM, Brest, France; pierre-amael.auger@ird.fr \\ 3 Department of Geophysics, University of Concepcion, Concepcion, Chile; Millennium Institute of \\ Oceanography (IMO), University of Concepcion, Concepcion, Chile; and School of Marine Sciences, \\ Pontifical Catholic University of Valparaiso, Valparaiso, Chile; katherine.gomez@imo-chile.cl \\ 4 International Pacific Research Center, School of Ocean and Earth Science and Technology, University of \\ Hawaii at Manoa, Honolulu, Hawaii, USA; maximenk@hawaii.edu \\ 5 Laboratoire d'Etudes en Géophysique et Océanographie Spatiale, Université de Toulouse, CNES, CNRS, \\ IRD, UPS, Toulouse, France; sophie.cravatte@legos.obs-mip.fr \\ * Correspondence: ali.belmadani@meteo.fr
}

\begin{abstract}
Eastern boundary upwelling systems feature strong zonal gradients of physical and biological ocean properties between cool, productive coastal oceans and warm, oligotrophic subtropical gyres. Zonal currents and jets (striations) are therefore likely to contribute to the transport of water properties between coastal and open oceanic regions. Multi-sensor satellite data are used to characterize the signatures of striations in sea surface temperature (SST), salinity (SSS), and chlorophyll-a (Chl-a) in subtropical eastern North/South Pacific (ENP/ESP) upwelling systems. In the ENP, tracers exhibit striated patterns extending up to $\sim 2500 \mathrm{~km}$ offshore. Striations in SST and SSS are highly correlated with quasi-zonal jets, suggesting that these jets contribute to SST/SSS mesoscale patterns via zonal advection. Chl-a striations are collocated with sea surface height (SSH) bands, a possible result of mesoscale eddy trains trapping nutrients and forming striated signals. In the ESP, striations are only found in SST and coincide with SSH bands, consistently with quasi-zonal jets located outside major zonal tracer gradients. An interplay between large-scale SST/SSS advection by the quasi-zonal jets, mesoscale SST/SSS advection by the large-scale meridional flow and eddy advection may explain the persistent ENP hydrographic striations. These results underline the importance of quasi-zonal jets for surface tracer structuring at the mesoscale.
\end{abstract}

Keywords: striations; satellite data; sea surface temperature; sea surface salinity; chlorophyll-a; eastern boundaries; Pacific Ocean

\section{Introduction}

Eastern boundary upwelling systems (EBUS) such as those found along the California and Chile coasts facing the eastern North and South Pacific subtropical gyres (Figure 1a) are unique regions known for their cool surface waters, extreme biological productivity and key influence on climate [1,2]. In sharp contrast, regions located further offshore are warmer and comparatively deprived from marine life. Oceanographic processes that exchange water between EBUS and neighboring oceanic regions are of particular interest because they may drive strong spatio-temporal variations in marine ecosystems and climate. Among such processes, mesoscale eddies are known to actively participate to cross-shelf transport of ocean properties [3,4]. 
Other structures that potentially contribute to these exchanges but have received less attention are striations, which are stationary multiple quasi-zonal jets that have recently been discovered throughout the world ocean and particularly in subtropical EBUS, using satellite, in situ, and model data [5-10] (Figure 1b). These bands of alternating eastward/westward mean geostrophic currents have meridional scales of 3$5^{\circ}$, extend from the surface to the intermediate or deep ocean, and spread out zonally for 1000's of km [11].
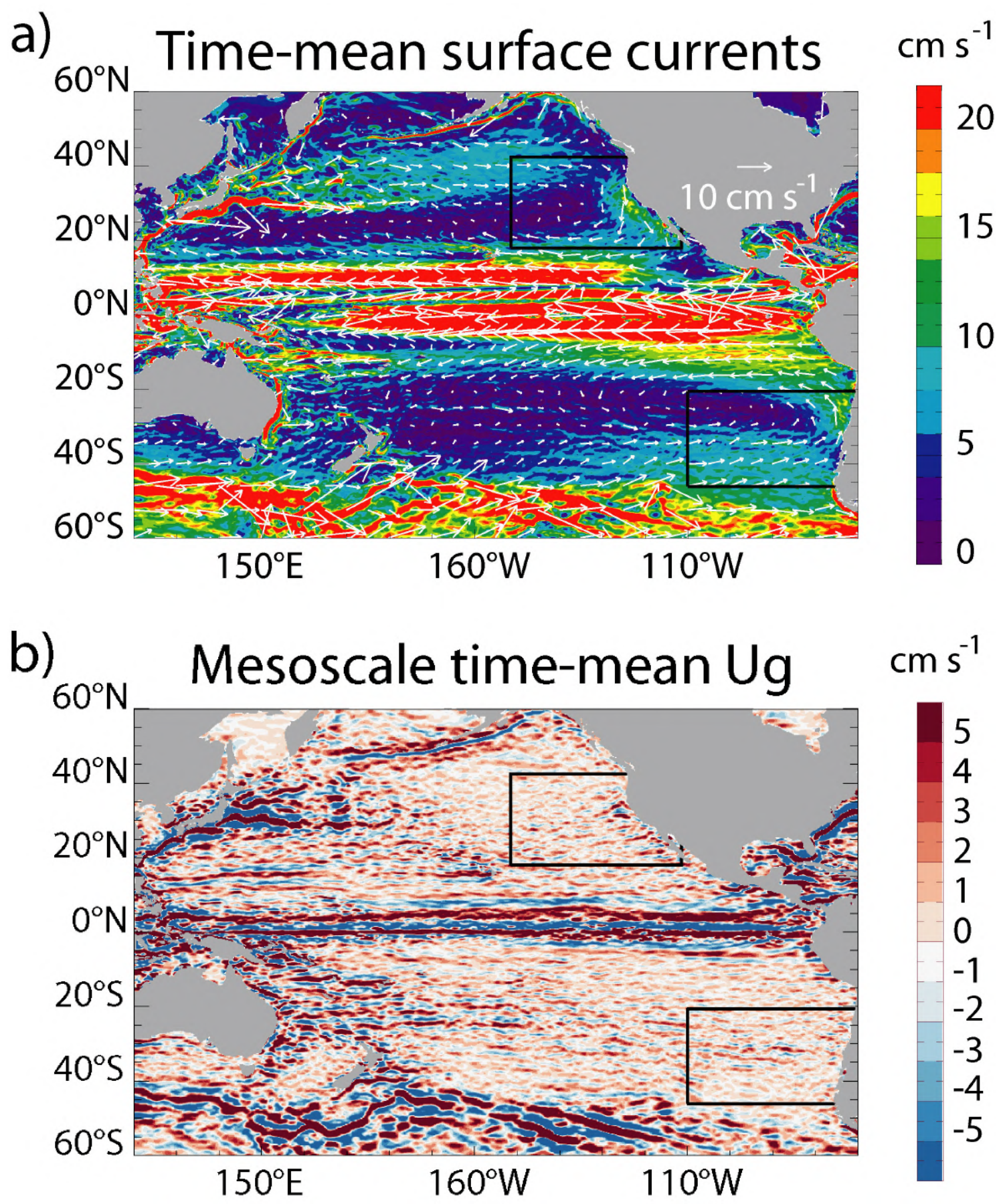

Figure 1. Surface circulation and quasi-zonal jets in the Pacific Ocean: (a) GlobCurrent surface current velocity (shading, $\mathrm{cm}$ $\mathrm{s}^{-1}$ ) and vectors, and (b) SSALTO/DUACS spatially high-pass filtered zonal geostrophic velocity $\mathrm{U}_{\mathrm{g}}$, averaged over 07/02/1212/31/18 (see Section 2 for a detailed description of the data and filtering method). The black boxes outline the two study regions off the California and Chile EBUS in the subtropical North and South Pacific, respectively.

Multiple theories have been proposed for their existence: artifacts of timeaveraging westward-propagating mesoscale eddies [12-14]; beta-plumes generated 
through Rossby wave or eddy radiation from eastern boundary current meanders [1517]; triad Rossby wave interaction and associated breaking [18-20]; anisotropic inverse energy cascades in geostrophic turbulence [21]; potential vorticity staircases associated with heterogeneous isopycnal mixing [22-23], just to name a few. Some of these theories were partly or entirely developed for EBUS [13,15,16,17].

In the Pacific subtropical EBUS, striations extend from the coast off California in the eastern North Pacific (ENP) but emerge farther offshore off Chile in the eastern South Pacific (ESP) (Figure 1b, see also Figures 2g, 3g), reflecting different generation mechanisms. California Current meanders anchored by coastline geometry provide vorticity sources, which generate Rossby waves/mesoscale eddies that propagate westward [16,24]. Similar processes are invoked in the ESP, except for vorticity sources driven by topographic steering of gyre flow over deep-ocean escarpments rather than by eastern boundary current instabilities [17].

Despite their weak amplitude $(\sim 1 \mathrm{~cm} / \mathrm{s})$, striations may advect the background temperature field [25], contribute to tracer mixing [23,26], ventilate oxygen minimum zones [27,28], transport floating debris [29], and modify surface winds [30], affecting marine ecosystems and climate. In particular, [26] showed from idealized modelling that striations may contribute much more to zonal mixing than eddies do when the background large-scale flow is predominantly zonal. The Lagrangian modelling study of [29] suggested the existence of an outflow from the ESP subtropical gyre dominated by striations, with its transport balancing $13-35 \%$ of convergence into the gyre. And [30]'s high-resolution coupled model study reported striated SST anomalies of \pm 0.05 $0.1^{\circ} \mathrm{C}$ off Peru in the tropical ESP as well as their impacts on the wind stress curl pattern. Considered together, these studies suggest that striations have a significant impact on water mass balances. Such effects may be further amplified in regions with strong along-striation (primarily zonal) physical and biogeochemical tracer gradients such as the cool, highly productive subtropical EBUS.

A complete understanding of the physical processes leading to the impact of striations on water masses is however missing. Zonal advection of background sea surface temperature (SST) in regions of well-defined zonal gradients like the tropical central/eastern South Pacific has been invoked in [30]'s modelling study. Conversely, [5] reported subsurface temperature anomalies in phase with the sea surface height (SSH) signature of striations in the ENP and ESP EBUS from in situ and model data. This implies that the striated mesoscale temperature field is in phase quadrature with the geostrophic current, which discards advection as the primary driver. [25] found that zonally-elongated satellite SST fronts were frequently associated with time-mean and transient striations. However, they focused on transient fronts within background meridional gradients and did not detail the relationship between time-mean fronts and striations. [23] found staircase-like meridional profiles in tropical Pacific subsurface salinity and oxygen cruise data, with fronts/homogeneous regions inside eastward/westward jets, respectively. Such structure was hypothesized by [25] in the presence of meridional large-scale gradients, which characterize subsurface tropical Pacific salinity and oxygen [23], and anticipated from the theories of [22] and [31]. Whether these findings are relevant to the extra-tropics and different background properties (e.g. zonal gradients) remains unclear.

Multi-year satellite records are now available not only for such variables as SST or ocean color as a proxy for surface chlorophyll-a (Chl-a), but recently also for the less studied sea surface salinity (SSS), allowing to grasp a broader picture of striation impacts on surface water masses. Here, we present observational evidence from multisensor data of striation effects on the aforementioned surface tracers in the North and South Pacific subtropical EBUS. In addition to SST and for the first time, SSS and Chl-a reveal contrasted footprints of striations in these climatically and biologically 
important regions. The differences found among the patterns in different variables and regions are attributed to the differences among large-scale tracer distributions and the embedded striations. Detailed analysis of advection terms from surface tracer equations is used to assess the dynamics responsible for the existence and persistence of striated SST and SSS signals in the ENP.

\section{Materials and Methods}

\subsection{Satellite Data}

Whenever possible and unless stated otherwise, the data are considered over a common period from July $2^{\text {nd }} 2012$ to December $31^{\text {st }} 2018$ for the ENP (defined as $\left.111.5^{\circ} \mathrm{W}-151.5^{\circ} \mathrm{W}, 22^{\circ} \mathrm{N}-47^{\circ} \mathrm{N}\right)$ and ESP $\left(70^{\circ} \mathrm{W}-110^{\circ} \mathrm{W}, 25^{\circ} \mathrm{S}-50^{\circ} \mathrm{S}\right)$. The time span of the shorter SSS dataset is specified in Section 2.1.3.

\subsubsection{SSH and Currents}

Altimetry data are used to characterize striations in SSH and geostrophic currents (e.g. Figure $1 \mathrm{~b})$. We used the daily gridded $\left(0.25^{\circ}\right)$ SSALTO/DUACS DT2018 delayedtime level-4 merged two-satellite product distributed by the Copernicus Climate Change Service. Absolute dynamic topography (i.e. SSH) and zonal geostrophic velocity $\left(\mathrm{U}_{\mathrm{g}}\right)$, available from 1993 onwards, were extracted for the study period.

Total surface currents including the Ekman flow are however required for the estimation of surface tracer advection (see Section 2.2). In particular, Ekman currents are expected to contribute significantly to large-scale surface flow and associated advection. We used the daily gridded $0.25^{\circ}$ GlobCurrent MULTIOBS_GLO_PHY_REP_015_004 level-4 product available from January $1^{\text {st }} 1993$ to May $31^{\text {st }} 2020$ and distributed by the Copernicus Marine Service [32]. It combines SSALTO/DUACS DT2018 altimetric geostrophic current and modeled Ekman surface current using wind stress from the European Centre for Medium-Range Weather Forecasts (ECMWF) ERA5 reanalysis [33].

Because the GlobCurrent and SSALTO/DUACS data are fully consistent in terms of the geostrophic currents that should dominate mesoscale velocities, another product is needed to test the sensitivity of striation properties to the choice of dataset (see Section 2.2). For this purpose, near-surface currents derived from altimeter SSH and scatterometer surface winds and consistent with Lagrangian drifter trajectories were obtained from the Surface CUrrents from Diagnostic model (SCUD) data available from APDRC/IPRC [34]. Daily gridded $\left(0.25^{\circ}\right)$ zonal $(\mathrm{U})$ and meridional (V) velocities are publicly available from February $14^{\text {th }} 2012$ to December $31^{\text {st }} 2018$.

\subsubsection{SST}

Following [25], remotely-sensed microwave data are used to extract the striated patterns in SST. We use 3-day average gridded $\left(0.25^{\circ}\right)$ Advanced Microwave Scanning Radiometer 2 (AMSR-2) [35] version 8 available from July $2^{\text {nd }} 2012$ onwards. The UK Met Office Group for High Resolution Sea Surface Temperature (GHRSST) Operational Sea surface Temperature and sea Ice Analysis (OSTIA) $0.05^{\circ}$ infrared data [36] exhibited mesoscale structures almost identical to AMSR-2 except in the coastal region (not shown), and were therefore discarded in subsequent analyses.

\subsubsection{SSS}

The SSS signature of striations is extracted from the NASA Soil Moisture Active Passive (SMAP) observatory [37], available from April $4^{\text {th }} 2015$ onwards. We used the JPL SMAP level-3 CAP standard mapped image 8-day running mean V4.3 validated $0.25^{\circ}$ daily data from April $4^{\text {th }} 2015$ to December $31^{\text {st }} 2018$ [38]. Soil Moisture Ocean Salinity (SMOS) data [39] have also been analyzed, but they were found much noisier 
in terms of mesoscale structures (not shown) and were not further considered in this study.

\subsubsection{Chl-a}

Striations in surface Chl-a are evaluated using satellite ocean color data. We use a merged product of the MODIS-AQUA and VIIRS datasets provided by the GlobColour project from July 2012 to December 2018. Monthly level-3 binned images ( $\sim 25 \mathrm{~km}$ resolution) include all level-2 products accumulated over one-month periods and merged using a bio-optical model-based procedure validated at the global scale [40].

\subsection{Data Processing and Analysis}

SSH and $\mathrm{U}_{\mathrm{g}}$ daily maps are time-averaged over the study period and spatially high-pass filtered with a $4^{\circ}$ half-width $2-\mathrm{D}$ Hanning window to extract stationary striations in dynamical fields ([17], and references therein). As shown by [17] and others, stationary striations are stable over time, and our results show little sensitivity to the exact averaging period. The same procedure is applied to daily U, SST, SSS, and monthly Chl-a. In the latter case, logarithmic transformation is applied beforehand to reduce the strong gradient between the oligotrophic open ocean and the productive EBUS (see Appendix A). Such transformation is commonly used for the analysis of Chl-a data (e.g. [41], their Appendix A and references therein). Note that although permutating log-transformation and 2-D filtering does not theoretically lead to identical results, they are similar despite somewhat noisier signals than the ones presented in Section 3. In such case, the computed large-scale component of Chl-a (which is removed to extract the mesoscale component, as for other variables [17]) is influenced by the strong near-zonal gradient, leading to possibly less accurate extraction of other large-scale features and therefore aliasing the extracted striations. Applying log-transformation first also allows assessing the impact of striations relative to background Chl-a (Appendix A). All the variables were filtered twice to remove any residual large-scale signal, which was significant for $\mathrm{SSH}$ and tracers after the first filter application (not shown).

Following [17], 2-D Fast Fourier Transform (FFT) is applied to the previously obtained mesoscale mean fields in order to compare the spatial scales of any striated patterns in the tracers and dynamical fields. For each variable and subdomain, FFT is computed in the area where tracer and dynamical striations are most evident from visual inspection (black dashed boxes on Figures 2 and 3). Such method was however unsuccessful for ENP Chl-a because of the very strong near-meridional, alongshore signal associated with exceptional coastal productivity that prevented the extraction of the weaker near-zonal signals in the coastal transition zone (Figures 2e,f). Approximate spatial scales for the striated signal in Chl-a are then estimated from FFT applied to a region that excludes the coastal band while capturing part of the striated pattern (orange dashed box on Figures 2e,f).

Besides zonal and meridional wavelengths, the average tilt of striations from the zonal direction is derived from the energy spectra. The angle of the dominant wave vector connecting the symmetric most energetic peaks is used for such purpose (white dashed lines on Figures 4, 5). In a few specific cases in the ESP $\left(U_{g}\right.$ averaged over the shorter SSS record, and SSH for both time spans, Figures 5e,g,h,i), secondary maxima with meridional wavelengths consistent with that found for the single peak in $U_{g}$ (averaged over the SST record, Figure 5d) were used instead. The angle obtained from the $\mathrm{U}_{\mathrm{g}}$ spectrum is used to average mesoscale fields in the along-striation direction (solid boxes on Figures 2 and 3), allowing to compare cross-striation profiles. For each tracer, cross-correlation with $\mathrm{SSH}$ and $\mathrm{U}_{\mathrm{g}}$ profiles is used to assess the possible role of zonal advection in striated pattern formation. Interpolating profiles at a $0.01^{\circ}$ resolution allows the computation of accurate lags. For each variable pair, the statistical significance at the $5 \%$ level of the correlation coefficient is computed using a 
Monte Carlo technique with 1000 iterations, where the first profile is correlated with a synthetic profile obtained from Fourier analysis of the second profile and a random phase [42].

a)

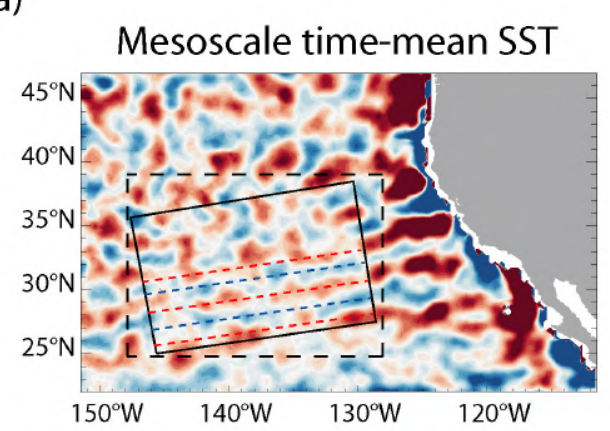

C)

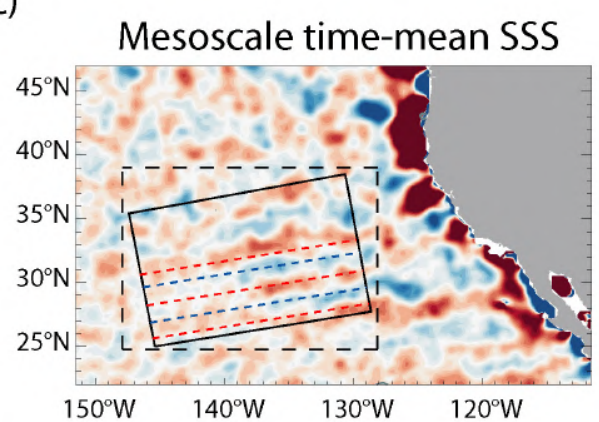

e)

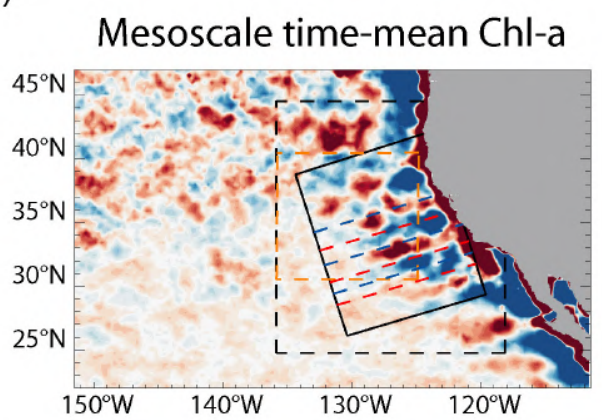

g)

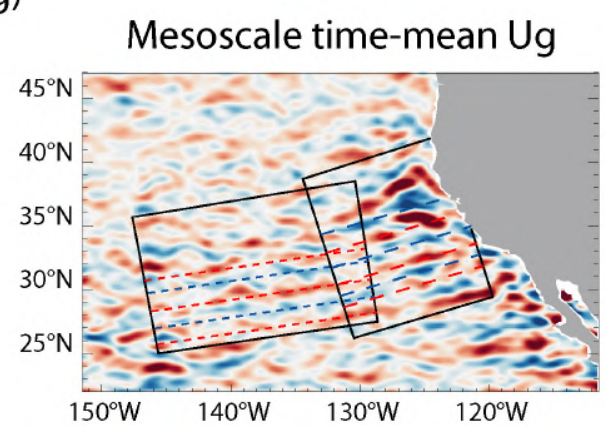

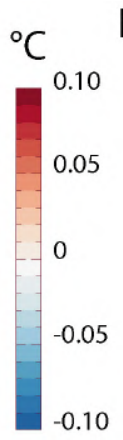

b)
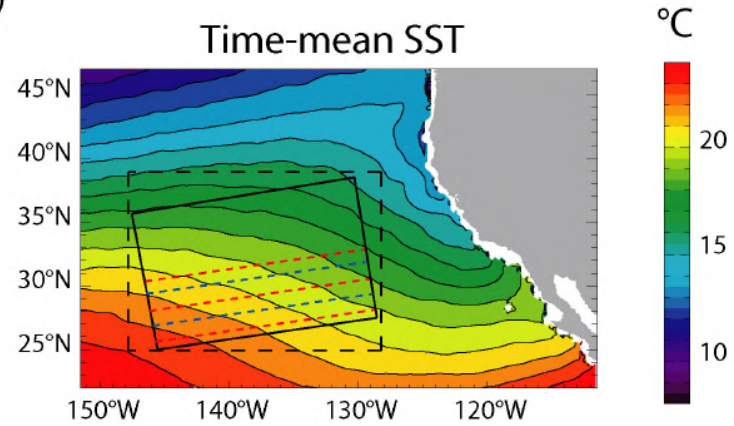

d)
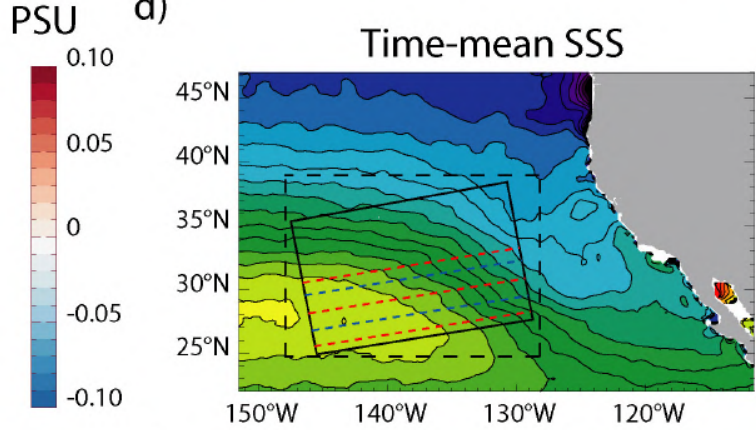

PSU

f)

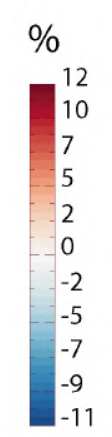

$45^{\circ}$
$40^{\circ}$
$35^{\circ}$
$30^{\circ}$
$25^{\circ}$

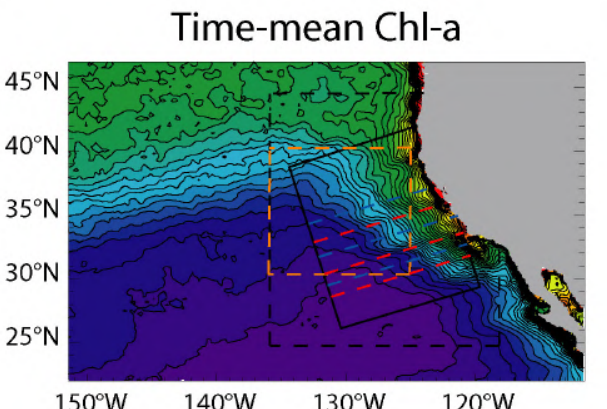

$\mathrm{mg} \mathrm{m}^{-3}$

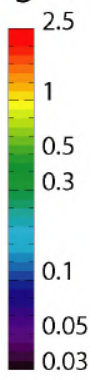

h)
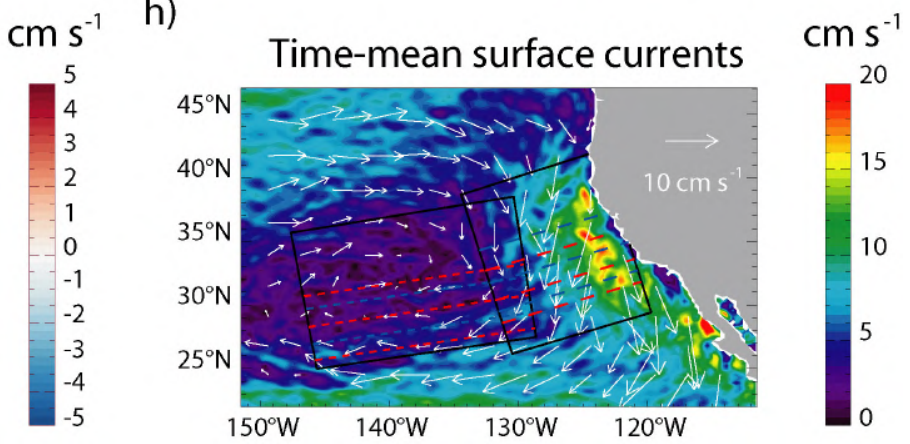

Figure 2. Striations in physical/biological tracers and currents in the ENP: mean (left) spatially high-pass filtered and (right) full (top row) AMSR-2 SST $\left({ }^{\circ} \mathrm{C}\right.$ ), (second row) SMAP SSS (PSU), (third row) GlobColour Chl-a; (bottom row) mean (left) spatially high-pass filtered SSALTO/DUACS $\mathrm{U}_{\mathrm{g}}\left(\mathrm{cm} \mathrm{s}^{-1}\right)$ and (right) GlobCurrent full surface current velocity (shading, $\mathrm{cm} \mathrm{s}^{-}$ ${ }^{1}$ ) and vectors. Chl-a units are $\mathrm{mg} \mathrm{m}^{-3}$ for (f) the full field and $\%$ of the latter for (e) the high-pass filtered field (Appendix A). The black dashed boxes are where 2-D FFT is applied to the tracer fields and $U_{g}$ except for (third row) Chl-a, for which the orange dashed box is used. The solid boxes are tilted with the striation angle in SSALTO/DUACS $U_{\mathrm{g}}$ determined from 2-D FFT. The associated tilted red and blue dashed lines on all the panels indicate the approximate locations of eastward and westward jets, respectively, as inferred from (g) SSALTO/DUACS $U_{g}$. The 07/02/12-12/31/18 averaging period is considered throughout, except (second row) where the 04/04/15-12/31/18 period is used due to shorter SSS record, resulting in slightly larger striation tilt $\left(9.7^{\circ}\right.$ vs. $8.8^{\circ}$, see Table 1$)$. 

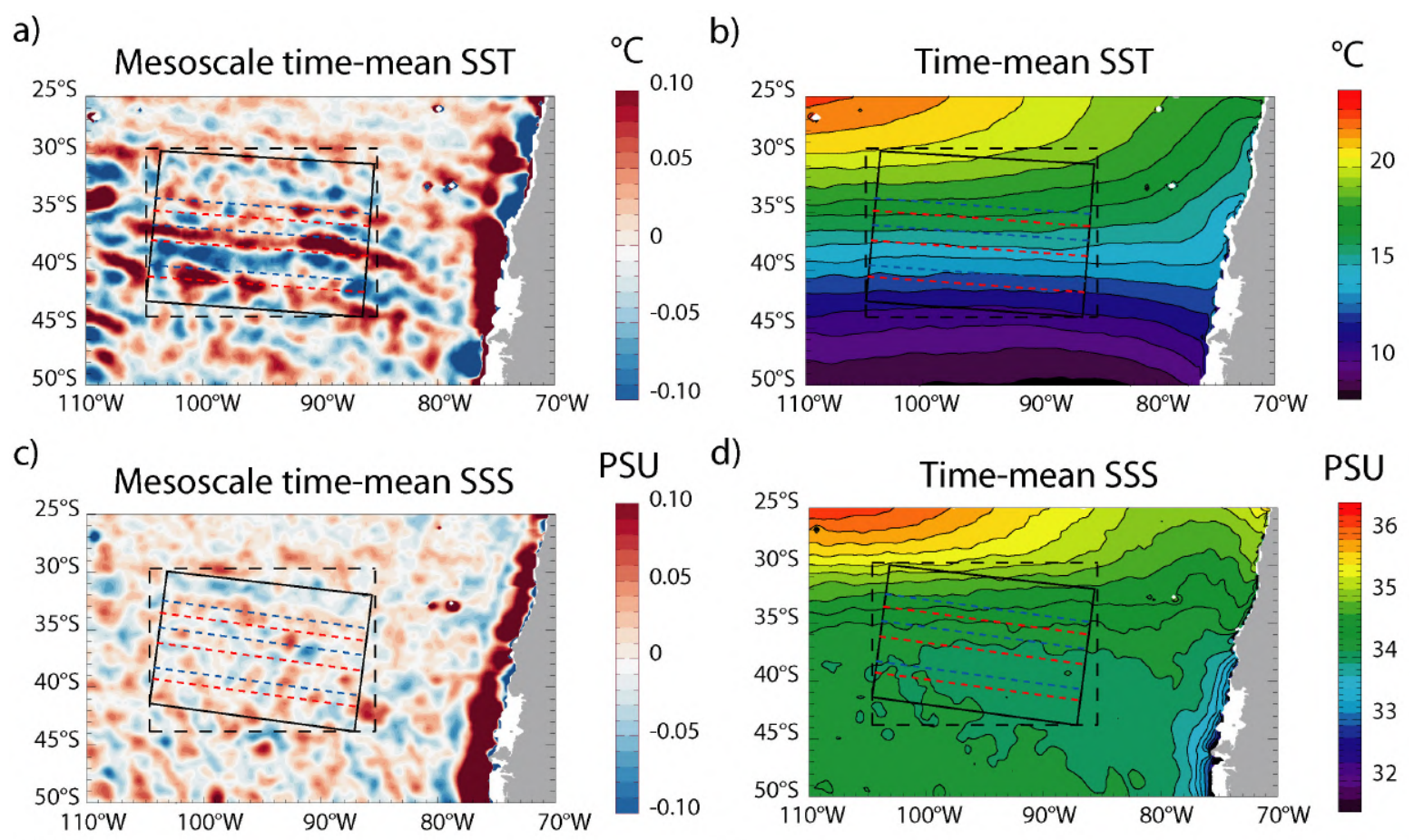

e)

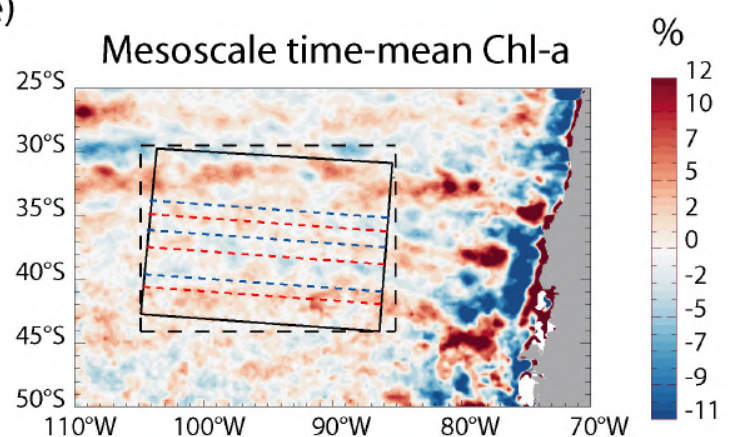

f)

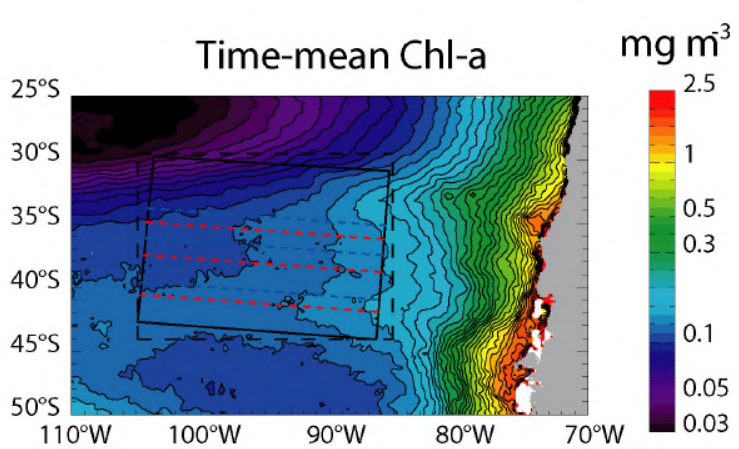

g)

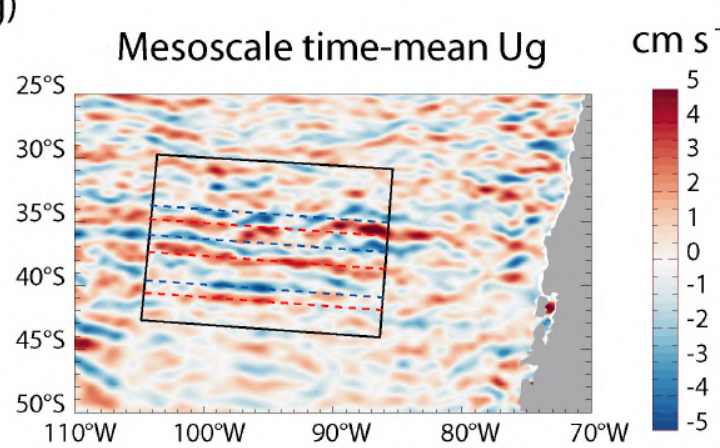

h)

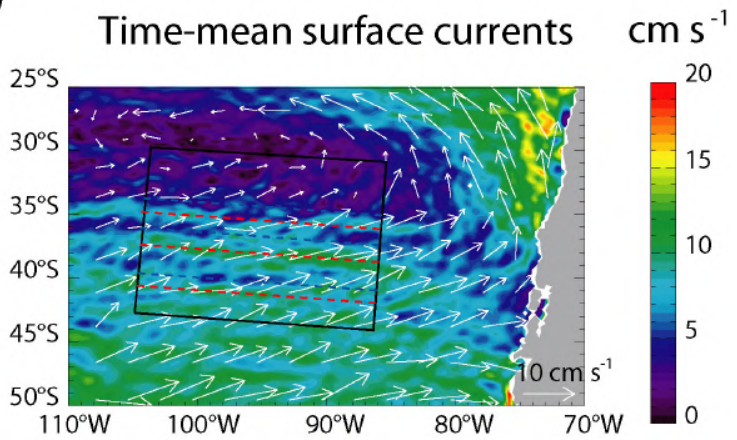

Figure 3. Striations in physical/biological tracers and currents in the ESP: mean (left) spatially high-pass filtered and (right) full (top row) AMSR-2 SST $\left({ }^{\circ} \mathrm{C}\right)$, (second row) SMAP SSS (PSU), (third row) GlobColour Chl-a; (bottom row) mean (left) spatially high-pass filtered SSALTO/DUACS $\mathrm{U}_{\mathrm{g}}\left(\mathrm{cm} \mathrm{s}^{-1}\right)$ and (right) GlobCurrent full surface current velocity (shading, $\mathrm{cm} \mathrm{s}^{-}$ ${ }^{1}$ ) and vectors. Chl-a units are $\mathrm{mg} \mathrm{m}^{-3}$ for (f) the full field and \% of the latter for (e) the high-pass filtered field (Appendix A). The black dashed boxes are where 2-D FFT is applied to the tracer fields and $U_{\mathrm{g}}$. The solid boxes are tilted with the striation angle in SSALTO/DUACS $\mathrm{U}_{\mathrm{g}}$ determined from 2-D FFT. The associated tilted red and blue dashed lines on all the panels indicate the approximate locations of eastward and westward jets, respectively, as inferred from (g) SSALTO/DUACS U. The 07/02/12-12/31/18 averaging period is considered throughout, except (second row) where the 04/04/15-12/31/18 period is used due to shorter SSS record, resulting in larger striation tilt $\left(12.7^{\circ}\right.$ vs. $5.8^{\circ}$, see Table 2$)$.

Finally, a decomposition of SST and SSS advection terms is computed in the ENP, where advection is found to play a dominant role (Section 3). However, striations being associated with eddy trains in subtropical gyres $[25,43]$ and particularly the ESP [17], both advection by the mean jets and nonlinear advection by individual eddies are candidate mechanisms. Moreover, additional processes should balance such advection 
in order to explain the persistence of hydrographic striations in multi-year averages (Section 3). The decomposition allows addressing these questions by separating nearzonal, along-striation advection from near-meridional, cross-striation advection; timemean fields from anomalies relative to the mean (Reynolds decomposition); and largescale components from mesoscale components for currents and hydrographical data.

a)

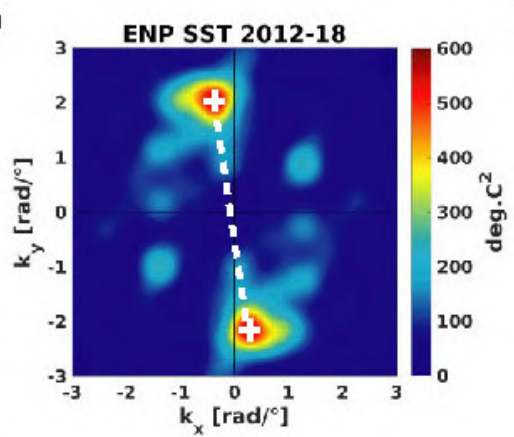

d)

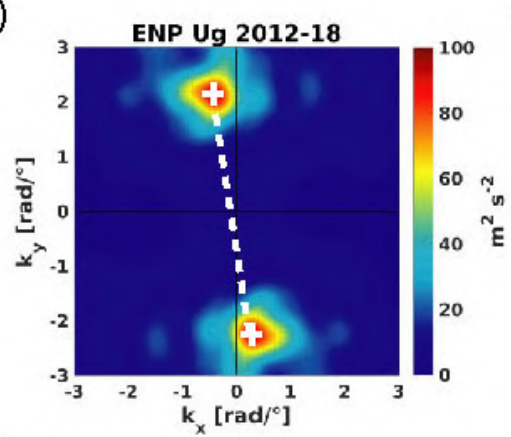

g)

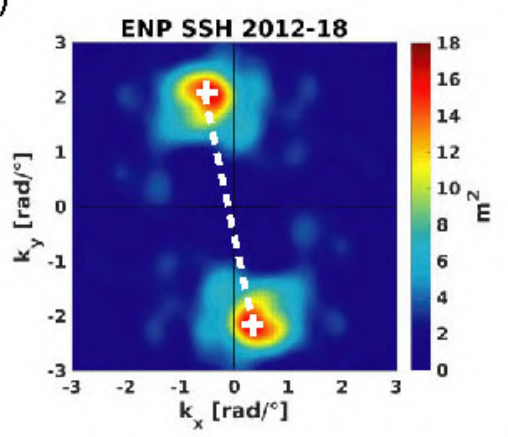

j)

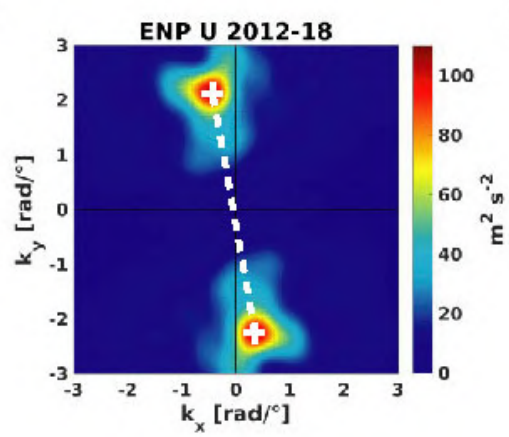

b)

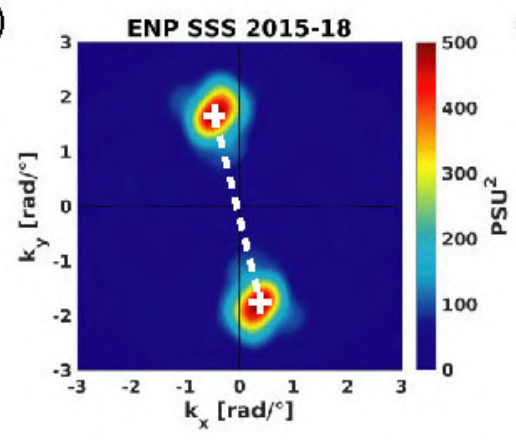

e)

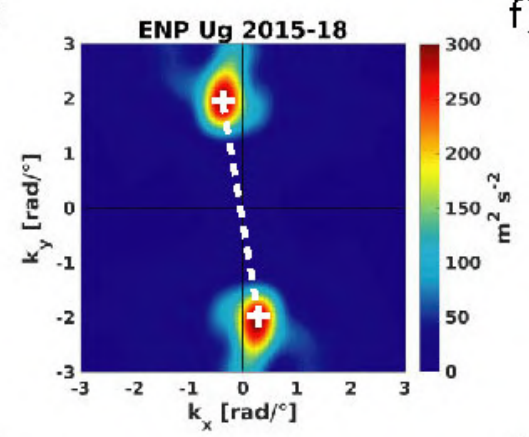

h)

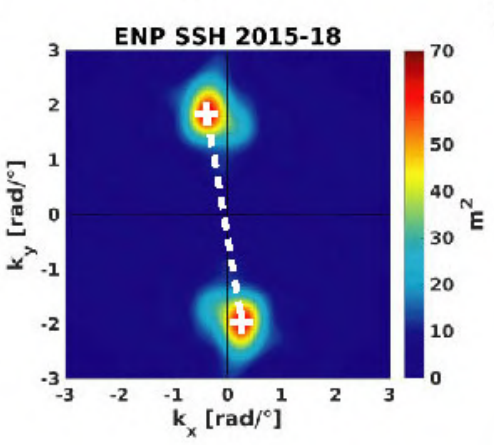

k)

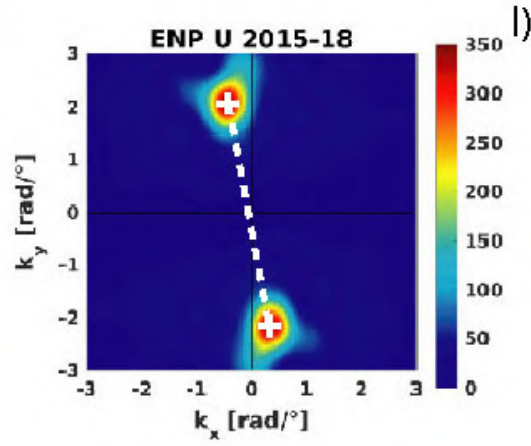

c)

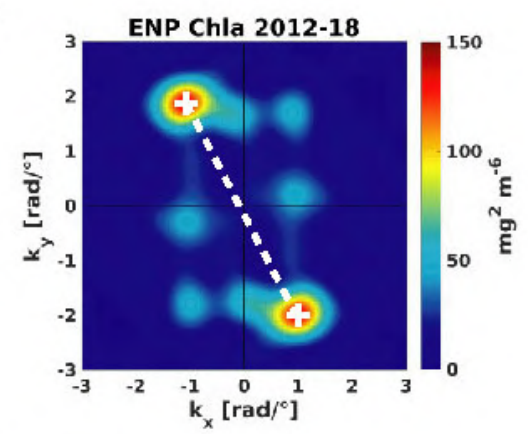

f)

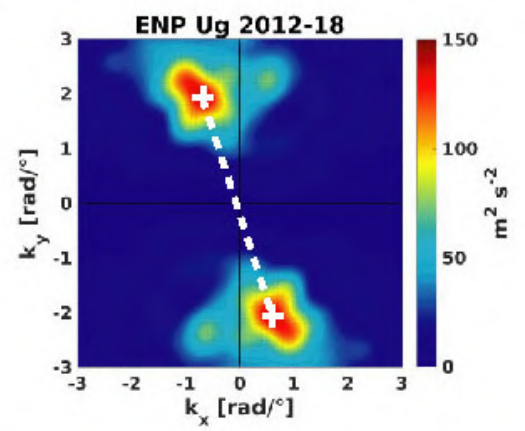

i)

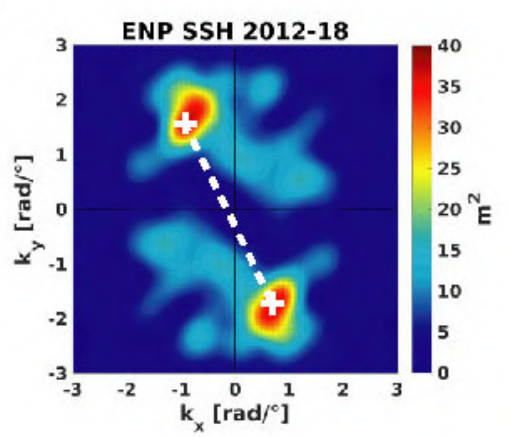

)

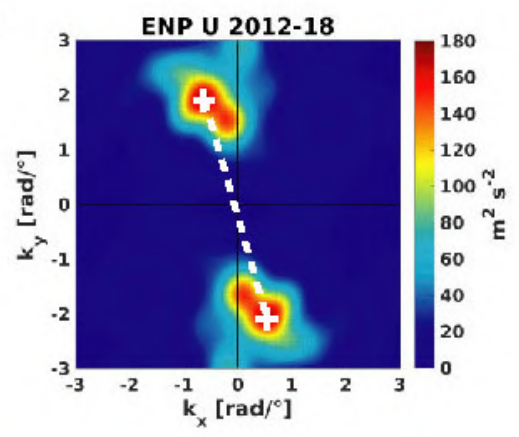

Figure 4. Spatial power spectra of mean spatially high-pass filtered fields in the ENP, computed within the dashed boxes on Figure 2. (a) AMSR-2 SST $\left({ }^{\circ} \mathrm{C}^{2}\right)$; (b) SMAP SSS (PSU $\left.{ }^{2}\right)$; (c) GlobColour Chl-a $\left(\mathrm{mg}^{2} \mathrm{~m}^{-6}\right)$; (d-f) SSALTO/DUACS $\mathrm{U}_{\mathrm{g}}\left(\mathrm{m}^{2} \mathrm{~s}^{-2}\right) ;(\mathrm{g}-\mathrm{i}) \mathrm{SSALTO} / \mathrm{DUACS} \mathrm{SSH}\left(\mathrm{m}^{2}\right) ;(\mathrm{j}-1) \mathrm{SCUD} U\left(\mathrm{~m}^{2} \mathrm{~s}^{-2}\right)$. The data are averaged over (left and right columns) 07/02/12-12/31/18 and (middle column) 04/04/15-12/31/18 in (left and middle columns) the offshore region and (right column) the coastal transition zone. The white crosses indicate the locations of the symmetric maxima, joined by the dashed lines indicating the direction of the dominant wave vector. 
a)

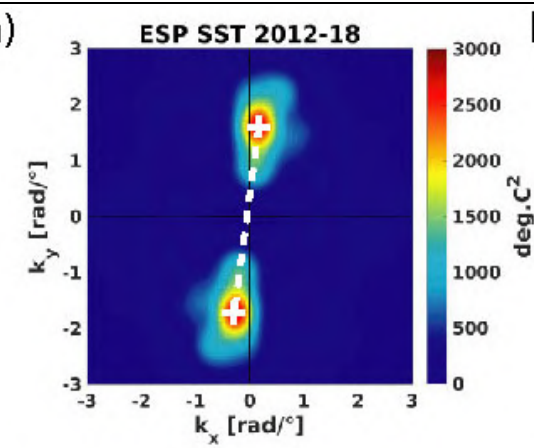

d)

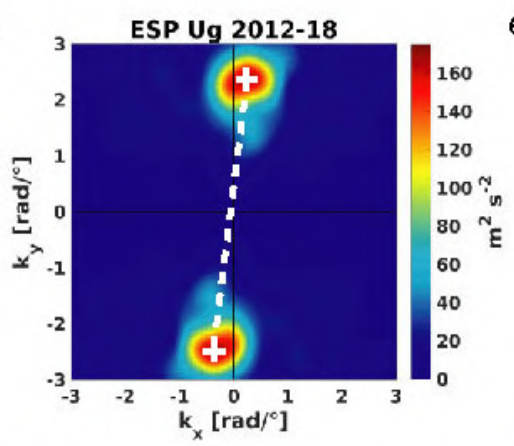

g)

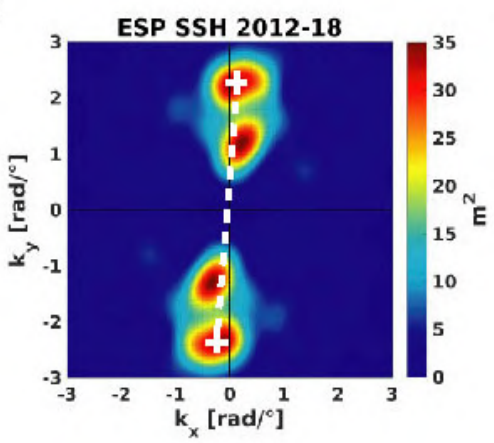

j)

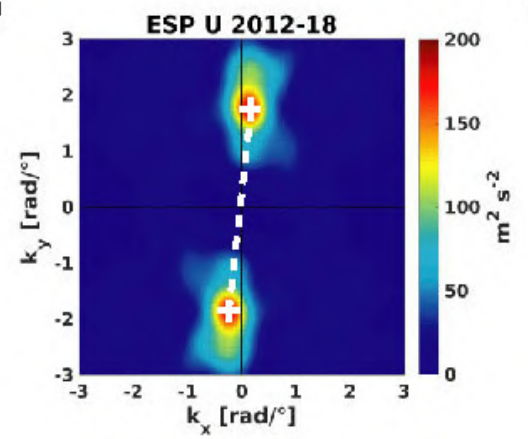

b)

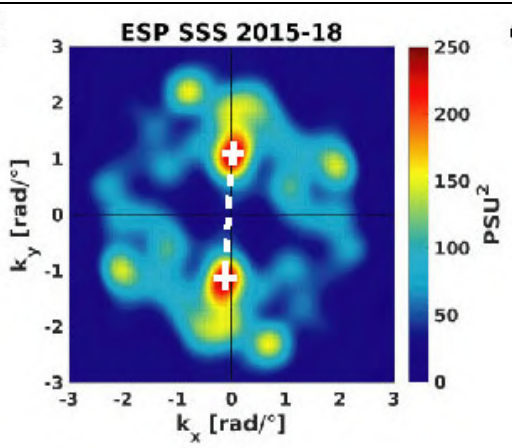

e)

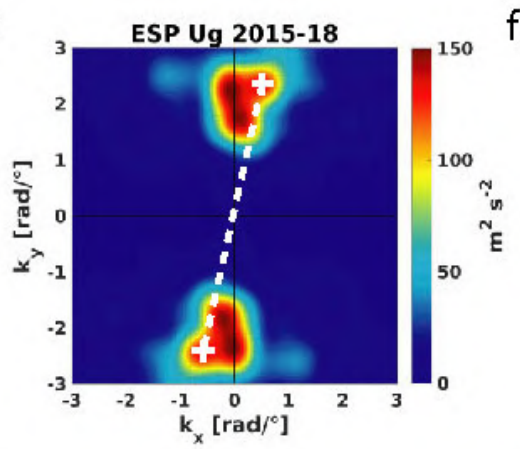

h)

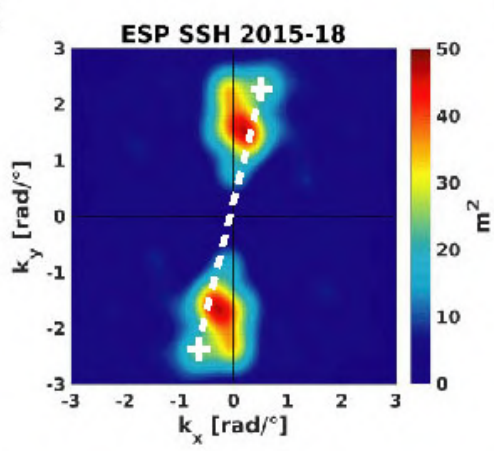

k)

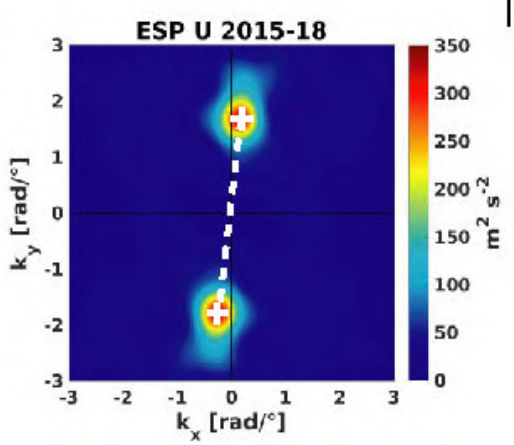

c)

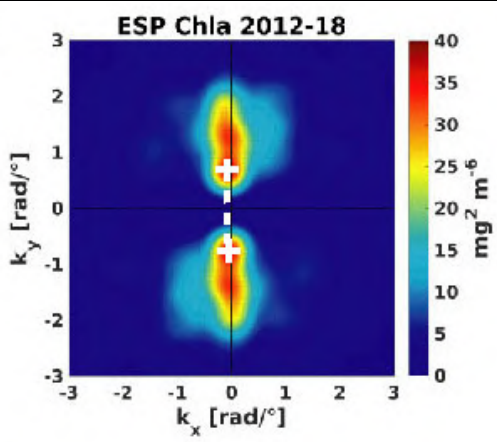

f)

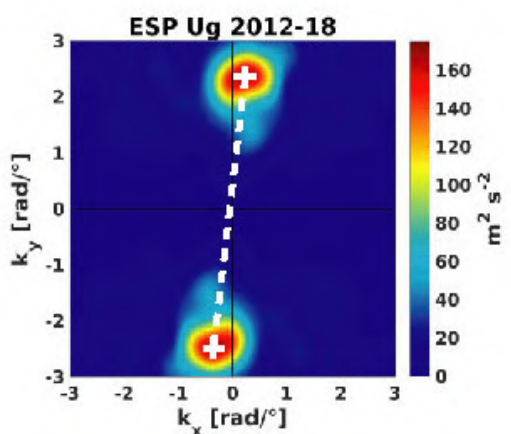

i)

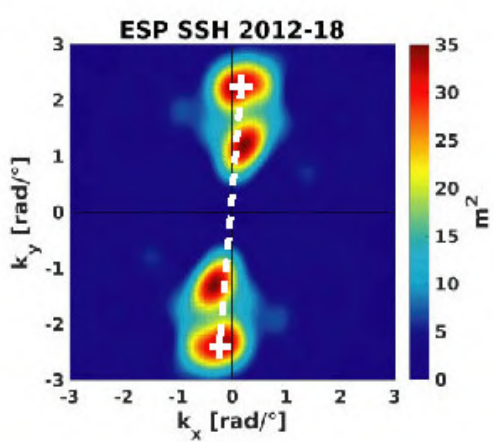

I)

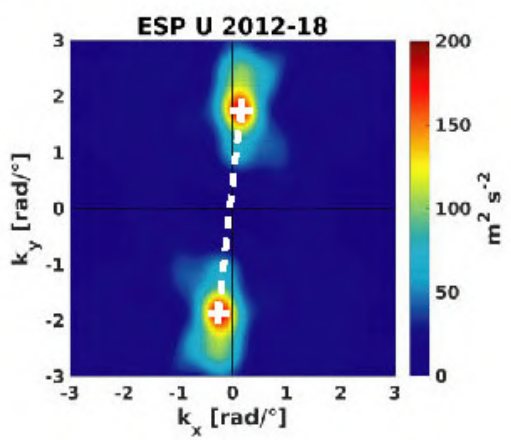

Figure 5. Spatial power spectra of mean spatially high-pass filtered fields in the ESP, computed within the dashed boxes on Figure 3. (a) AMSR-2 SST $\left({ }^{\circ} \mathrm{C}^{2}\right)$; (b) SMAP SSS (PSU $\left.{ }^{2}\right)$; (c) GlobColour Chl-a $\left(\mathrm{mg}^{2} \mathrm{~m}^{-6}\right)$; (d-f) SSALTO/DUACS $\mathrm{U}_{\mathrm{g}}\left(\mathrm{m}^{2} \mathrm{~s}^{-2}\right)$; $(\mathrm{g}$-i) SSALTO/DUACS SSH $\left(\mathrm{m}^{2}\right) ;(\mathrm{j}-1)$ SCUD U $\left(\mathrm{m}^{2} \mathrm{~s}^{-2}\right)$. The data are averaged over (left and right columns) 07/02/12-12/31/18 and (middle column) 04/04/15-12/31/18. Panels on the left and right columns are identical (except top row) because SST and Chl-a are analyzed over the same region and period. The white crosses indicate the locations of the symmetric maxima (local maxima on $\mathrm{e}, \mathrm{g}, \mathrm{h}, \mathrm{i}$ ), joined by the dashed lines indicating the direction of the dominant wave vector (or wave vector consistent with striations).

The general equation of a surface hydrographical tracer $F$ (either SST or SSS) is:

$$
\partial F / \partial t=-V \nabla F+\nabla(K \nabla F)+\text { fluxes }
$$

where $t$ represents time, $V$ is the surface velocity vector, and $K$ is for diffusivity. The term on the left hand side represents local (Eulerian) time derivative of $F$ (or tendency). It is driven by the three terms on the right hand side: from left to right, advection by ocean currents (both horizontal and vertical), turbulent mixing (horizontal and 
vertical), and fluxes at the ocean surface or along continental boundaries (such as heat/freshwater air-sea fluxes and river runoff).

In this study, we focus on stationary striated patterns at the ocean surface, where horizontal advection is expected to dominate. In a near-Cartesian orthogonal frame slightly rotated counterclockwise and aligned with mean striation axis, horizontal advection of $F$ may be written as:

$$
-V \nabla_{H} F=-u_{a} \partial F / \partial x_{a}-v_{c} \partial F / \partial y_{c},
$$

where $u_{a}$ and $v_{c}$ are the along-striation and cross-striation components of $V$, and $x_{a}$ and $y_{c}$ are along-striation and cross-striation coordinates, respectively. The terms on the right hand side of (2) represent along-striation and cross-striation advection of $F$.

A Reynolds decomposition is then applied to the surface currents and tracer:

$$
\begin{aligned}
& u_{a}=u_{a}{ }^{\prime}+\overline{u_{a}} \\
& v_{C}=v_{C^{\prime}}{ }^{\prime}+\overline{v_{c}} \\
& F=F^{\prime}+\bar{F}
\end{aligned}
$$

where overbars are for time-averaging over the available record and prime marks are for anomalies relative to the time-averaged fields.

Averaging (2) over time yields:

$$
-\overline{V \nabla_{H} F}=-\overline{u_{a}{ }^{\prime} \partial F^{\prime} / \partial x_{a}}-\overline{u_{a}} \partial \bar{F} / \partial x_{a}-\overline{v_{c}{ }^{\prime} \partial F^{\prime} / \partial y_{c}}-\overline{v_{c}} \partial \bar{F} / \partial y_{c}
$$

The terms on the right hand side of (6) represent the long-term averages of nonlinear (or eddy) along-striation advection, mean along-striation advection, nonlinear crossstriation advection, and mean cross-striation advection, respectively.

Finally, spatial scale separation is applied to the anomalous and mean surface currents and tracer:

$$
\begin{gathered}
u_{a}{ }^{\prime}+\overline{u_{a}}=u_{a L}{ }^{\prime}+u_{a H}{ }^{\prime}+\overline{u_{a L}}+\overline{u_{a H}} \\
v_{c}{ }^{\prime}+\overline{v_{c}}=v_{c L}{ }^{\prime}+v_{c H}{ }^{\prime}+\overline{v_{c L}}+\overline{v_{c H}} \\
F^{\prime}+\bar{F}=F_{L}{ }^{\prime}+F_{H}{ }^{\prime}+\overline{F_{L}}+\overline{F_{H}},
\end{gathered}
$$

where $H$ and $L$ subscripts refer to mesoscale and large-scale components obtained from spatial high-pass filtering with a $4^{\circ}$ half-width 2-D Hanning window.

$$
\begin{aligned}
\text { Incorporating (7), (8), and (9) into (6) gives: } & \\
-\overline{V \nabla_{H} F}= & -\left(\overline{u_{a L}{ }^{\prime} \partial F_{L}{ }^{\prime} / \partial x_{a}}+\overline{u_{a L}{ }^{\prime} \partial F_{H}{ }^{\prime} / \partial x_{a}}+\overline{u_{a H}{ }^{\prime} \partial F_{L}{ }^{\prime} / \partial x_{a}}+\overline{u_{a H}{ }^{\prime} \partial F_{H}{ }^{\prime} / \partial x_{a}}\right) \\
& -\left(\overline{u_{a L}} \partial \overline{F_{L}} / \partial x_{a}+\overline{u_{a L}} \partial \overline{F_{H}} / \partial x_{a}+\overline{u_{a H}} \partial \overline{F_{L}} / \partial x_{a}+\overline{u_{a H}} \partial \overline{F_{H}} / \partial x_{a}\right) \\
& -\left(\overline{v_{c L}{ }^{\prime} \partial F_{L}{ }^{\prime} / \partial y_{c}}+\overline{v_{c L}{ }^{\prime} \partial F_{H}{ }^{\prime} / \partial y_{c}}+\overline{v_{c H}{ }^{\prime} \partial F_{L}{ }^{\prime} / \partial y_{c}}+\overline{v_{c H}{ }^{\prime} \partial F_{H}{ }^{\prime} / \partial y_{c}}\right) \\
& -\left(\overline{v_{c L}} \partial \overline{F_{L}} / \partial y_{c}+\bar{v}_{c L} \partial \overline{F_{H}} / \partial y_{c}+\overline{v_{c H}} \partial \overline{F_{L}} / \partial y_{c}+\overline{v_{c H}} \partial \overline{F_{H}} / \partial y_{c}\right) \quad(10)
\end{aligned}
$$

The sixteen terms on the right hand side of (10) are the considered SST/SSS advection terms. After 2-D mapping, cross-striation profiles are computed and key terms are cross-correlated as described above.

\section{Results}

\subsection{Striated Surface Tracers}

Figure 2 shows the time-averaged, spatially filtered and full (raw, unfiltered) satellite surface tracer and current observations in the ENP. Striated signals in SST and SSS are visible over a large region extending between the California coast and $\sim 145^{\circ} \mathrm{W}$ (Figures 2a,c). Despite the weak signals, with values of $\sim 0.05^{\circ} \mathrm{C}$ and $0.05 \mathrm{PSU}$, striations stand out slightly above noise level $\left(\sim 0.04^{\circ} \mathrm{C}\right.$ and 0.03 PSU, see Appendix B), are zonally coherent, and appear connected to stronger signals closer to the coast, suggesting they are likely real features. Similar meridionally-alternating bands are found in Chl-a data with magnitudes reaching $10 \%$ of full Chl-a but they do not extend beyond $\sim 500 \mathrm{~km}$ offshore (Figure $2 \mathrm{e}$ ). Meridional wavelengths $\mathrm{L}_{\mathrm{y}}$ inferred from 
spectral analysis (Figure 4) range from $3.0^{\circ}$ to $3.7^{\circ}$ for different tracers, and striation axes are tilted counterclockwise from the zonal orientation by an angle $\alpha$ varying from $9.2^{\circ}$ to $14.4^{\circ}\left(28.9^{\circ}\right.$ for Chl-a, Table 1$)$. These figures agree well with the dynamical fields $\left(\mathrm{U}, \mathrm{U}_{\mathrm{g}}, \mathrm{SSH}\right.$ ) having $\mathrm{L}_{\mathrm{y}}$ range from $2.8^{\circ}$ to $3.9^{\circ}$ and $\alpha$ from $8.8^{\circ}$ to $11.3^{\circ}\left(17.6^{\circ}\right.$, $17.6^{\circ}$, and $27.3^{\circ}$ for $\mathrm{U}, \mathrm{U}_{\mathrm{g}}$, and $\mathrm{SSH}$ in the region with striated Chl-a signals). Remarkably, warm and salty (cool and fresh) anomalies are aligned with eastward (westward) jets (Figures 2a,c,g), suggesting they may result from advection by the striated currents. Indeed, the region through which the jets extend southwestward has strong background along-striation gradients of SST and SSS (Figures $2 b, d$ ) between the California EBUS and the subtropical gyre (Figure 2h). In contrast, the striated geostrophic velocities tend to coincide with zero-crossings of Chl-a anomalies, i.e. bands of locally more (less) productive waters are collocated with negative (positive) meridional shear of near-zonal jets, that is, along striation troughs (crests) (Figures $2 \mathrm{e}, \mathrm{g})$. Interestingly, the offshore extent of Chl-a striations corresponds to that of the background Chl-a gradient between coastal and open-ocean waters (Figure 2f).

Table 1. Zonal and meridional wavelengths $\left(\mathrm{L}_{\mathrm{x}}, \mathrm{L}_{\mathrm{y}}\right)$, and striation angle $(\alpha)$ for surface tracers and dynamical fields determined from 2-D FFT in the ENP (Figure 4). For dynamical fields over the SST/Chl-a record (2012-18), values on the left/right correspond to the boxes on Figure 2a/Figure 2e, respectively. Positive/negative $\alpha$ values are clockwise/counterclockwise.

\begin{tabular}{|c|c|c|c|c|c|c|c|c|c|}
\hline Variable & $\mathrm{U}$ & & $\mathrm{U}_{\mathrm{g}}$ & & SSH & & SST & SSS & Chl-a \\
\hline Period & $2012-18$ & $2015-18$ & $2012-18$ & $2015-18$ & $2012-18$ & $2015-18$ & $2012-18$ & $2015-18$ & $2012-18$ \\
\hline $\mathrm{L}_{\mathrm{x}}\left({ }^{\circ}\right)$ & $14.2 / 9.8$ & 18.3 & $18.3 / 9.8$ & 18.3 & 18.3/7.5 & 18.3 & 18.3 & 14.2 & 6.1 \\
\hline $\mathrm{L}_{\mathrm{y}}\left({ }^{\circ}\right)$ & $2.8 / 3.1$ & 3.0 & $2.8 / 3.1$ & 3.1 & $3.0 / 3.9$ & 3.3 & 3.0 & 3.7 & 3.3 \\
\hline$\alpha\left(^{\circ}\right)$ & $-11.3 /-17.6$ & -9.2 & $-8.8 /-17.6$ & -9.7 & $-9.2 /-27.3$ & -10.2 & -9.2 & -14.4 & -28.3 \\
\hline
\end{tabular}

Table 2. Zonal and meridional wavelengths $\left(\mathrm{L}_{x}, \mathrm{~L}_{\mathrm{y}}\right)$, and striation angle $(\alpha)$ for surface tracers and dynamical fields determined from 2-D FFT in the ESP (Figure 5). Positive/negative $\alpha$ values are clockwise/counterclockwise.

\begin{tabular}{cccccccccc}
\hline Variable & $\mathbf{U}$ & \multicolumn{3}{c}{$\mathbf{U}_{\mathrm{g}}$} & SSH & SST & SSS & Chl-a \\
\hline Period & $2012-18$ & $2015-18$ & $2012-18$ & $2015-18$ & $2012-18$ & $2015-18$ & $2012-18$ & $2015-18$ & $2012-18$ \\
$\mathrm{~L}_{\mathrm{x}}\left({ }^{\circ}\right)$ & 42.7 & 25.6 & 25.6 & 11.6 & 42.7 & 11.4 & 25.6 & 128 & 128 \\
$\mathrm{~L}_{\mathrm{y}}\left({ }^{\circ}\right)$ & 3.5 & 3.7 & 2.6 & 2.6 & 2.7 & 2.7 & 3.7 & 5.6 & 8.5 \\
$\alpha\left({ }^{\circ}\right)$ & 4.6 & 8.1 & 5.8 & 12.7 & 3.7 & 13.2 & 8.1 & 2.5 & -3.8 \\
\hline
\end{tabular}

The same analysis yields strikingly different results for the ESP. While multiple near-zonal SST bands of amplitude $\sim 0.1^{\circ} \mathrm{C}$ (again slightly above standard error $\sim 0.07^{\circ} \mathrm{C}$, Appendix B) are evident in a region far offshore central Chile (Figure 3a), SSS and Chl-a patterns are noisier (Figures $3 \mathrm{c}, \mathrm{e}$ ). Spectral analysis confirms that the mesoscale properties of the SSS and Chl-a fields are inconsistent with those of the dynamical fields (Figure 5). $\mathrm{L}_{\mathrm{y}}$ are larger in the former (5.6-8.5 $\left.5^{\circ} \mathrm{vs} .2 .6-3.7^{\circ}\right)$ and $\alpha$ are smaller (-3.8-2.5 ${ }^{\circ}$ vs. $\left.3.7-13.2^{\circ}\right)$ (Table 2). Let us however note that similarly to the ENP, some kind of banded structure is detected for mesoscale Chl-a in the coastal transition region, although with reduced zonal extent and away from the most obvious quasizonal jets located farther offshore along the subtropical gyre poleward edge (Figures $3 \mathrm{e}, \mathrm{g}, \mathrm{h})$. On the other hand, the values found for SST are within the range of those extracted from dynamical fields (Table 2). Besides, striations in SST tend to be in phase quadrature rather than in phase with those in $U_{g}$ (Figures 3a,g). Part of the differences from the ENP may reside in different jet locations relative to large-scale tracer fields. As subtropical EBUS, both systems exhibit similar gradients of SST, SSS, and Chl-a (Figures $2 \mathrm{~b}, \mathrm{~d}, \mathrm{f}$ and $3 \mathrm{~b}, \mathrm{~d}, \mathrm{f}$ ). However, unlike the ENP (Figure 2g), ESP striations are observed farther offshore and do not extend eastward to the coast (Figure 3g), consistently with distinct formation processes $[16,17]$. As a result, ESP striations are 
found within weak zonal gradients of SST, SSS, and Chl-a (Figures $3 b, d, f, g)$. On the other hand, this region features a strong meridional SST gradient between the subtropical gyre and higher latitudes. Phase quadrature between striations in SST and $\mathrm{U}_{\mathrm{g}}$ then implies that eastward (westward) jets correspond to mesoscale meridional SST gradients that sharpen (flatten) the large-scale gradient, in qualitative agreement with [23]. Mesoscale gradients are however too weak $\left(<10^{-3}{ }^{\circ} \mathrm{C} \mathrm{km}^{-1}, \sim 1 / 10\right.$ of the large-scale gradient) to generate any significant staircase profile in raw SST.

To further support our findings and more objectively assess the relationship between surface tracers and either $\mathrm{U}_{\mathrm{g}}$ or $\mathrm{SSH}$, variables are averaged in the alongstriation direction and in the area where striations are most evident (solid boxes on Figures 2 and 3), before cross-striation profiles are computed (Figure 6). Lagcorrelation analysis confirms that near-periodic ENP SST and SSS are both highly $(\sim 0.8)$ and significantly correlated with $\mathrm{U}_{\mathrm{g}}$, with a small lag of about $0.1-0.2^{\circ}$ (Figures $6 a, b)$. Correlations are also high $(\sim 0.9)$ and statistically significant with SSH but with larger lag ( $\sim 0.6-0.7^{\circ}$ latitude) in the opposite direction, consistently with nearquadrature and dominant periodicity $\mathrm{L}_{\mathrm{y}} \sim 3^{\circ}$. Conversely, Chl-a and SSH $\left(\mathrm{U}_{\mathrm{g}}\right)$ exhibit high, statistically significant negative correlation $\sim 0.7-0.8$ with meridional lag $\sim-0.25^{\circ}$ $\left(\sim+0.5^{\circ}\right)$ (Figure $6 \mathrm{c}$ ). In addition, correlation at zero lag is significant with SSH only and higher $(-0.64)$ compared to $U_{g}(-0.40)$. This confirms that zonal advection is not the dominant driver for striations in Chl-a, unlike physical tracers.

In the ESP, SST and SSH are approximately in phase, particularly between $37^{\circ} \mathrm{S}$ and $41^{\circ} \mathrm{S}$ (Figure $6 \mathrm{~d}$ ) with high $(\sim 0.8)$, statistically significant correlation. Quadrature with $\mathrm{U}_{g}$, particularly evident also from $37^{\circ} \mathrm{S}$ to $41^{\circ} \mathrm{S}$, is confirmed with maximum correlation $\sim 0.7$ at lag $-0.8^{\circ}$. On the other hand, SSS and Chl-a appear poorly correlated with SSH and $\mathrm{U}_{\mathrm{g}}$ (Figures 6e,f). In fact, SSS and Chl-a profiles do not exhibit clear periodicity, unlike SST and dynamical fields. Note that these results did not change much when the striation angle from SSH instead of $U_{g}$ was used to compute alongstriation averages (not shown), consistently with the generally similar $\alpha$ values (Tables $1,2)$. 
a)

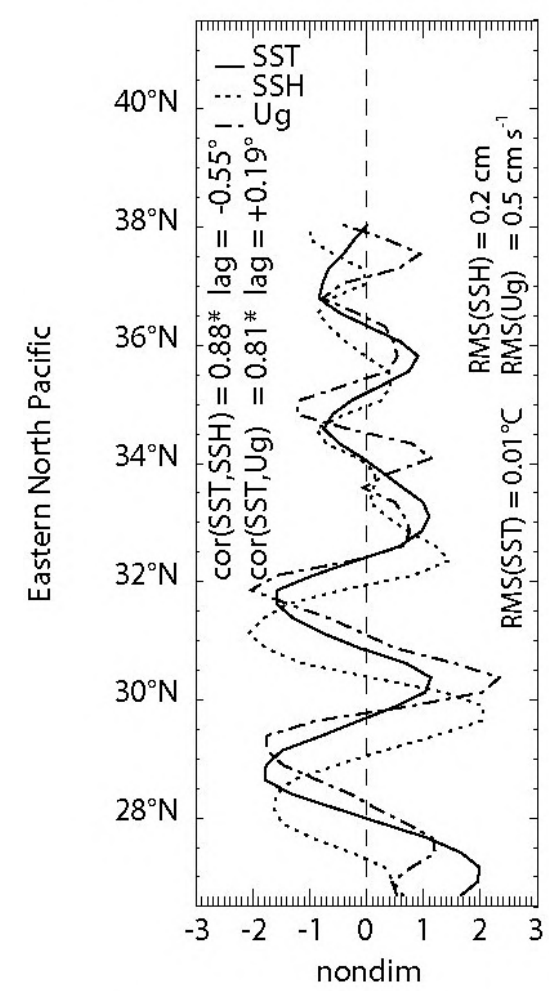

d)

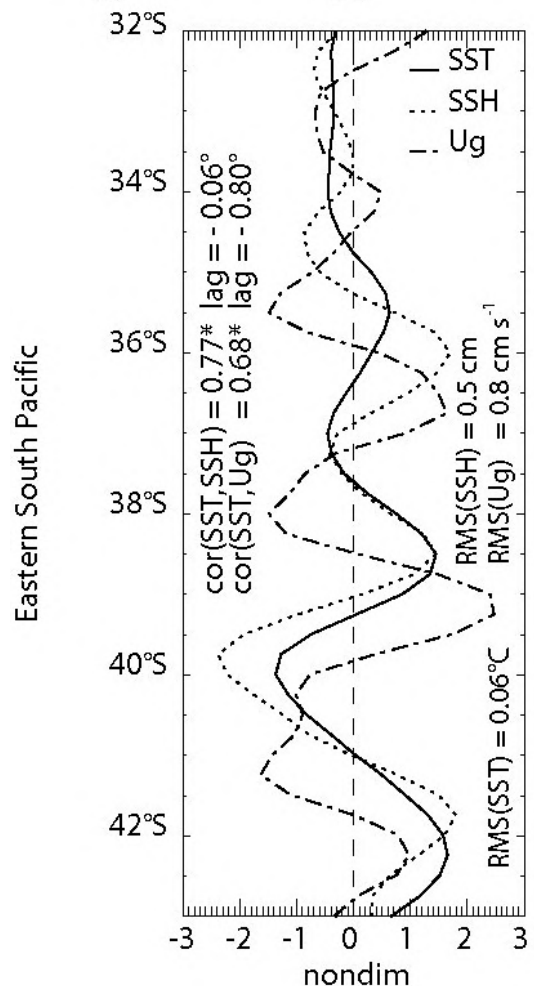

b)

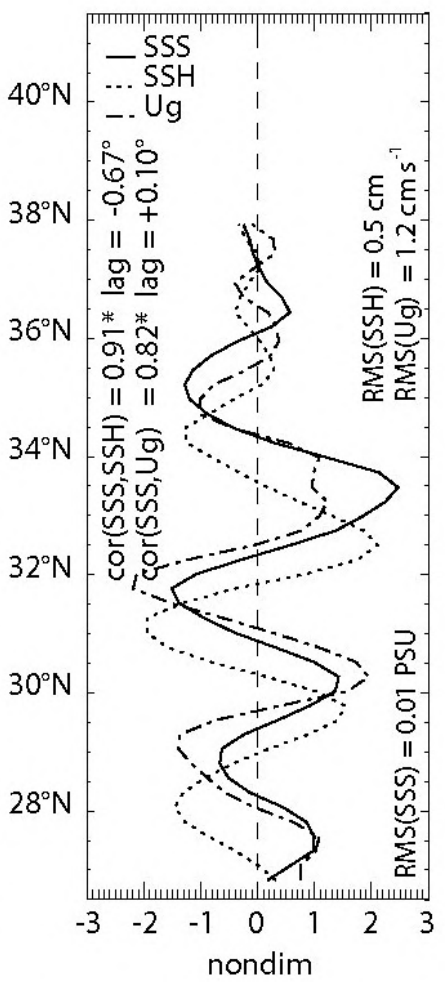

e)

$32^{\circ} \mathrm{S}$

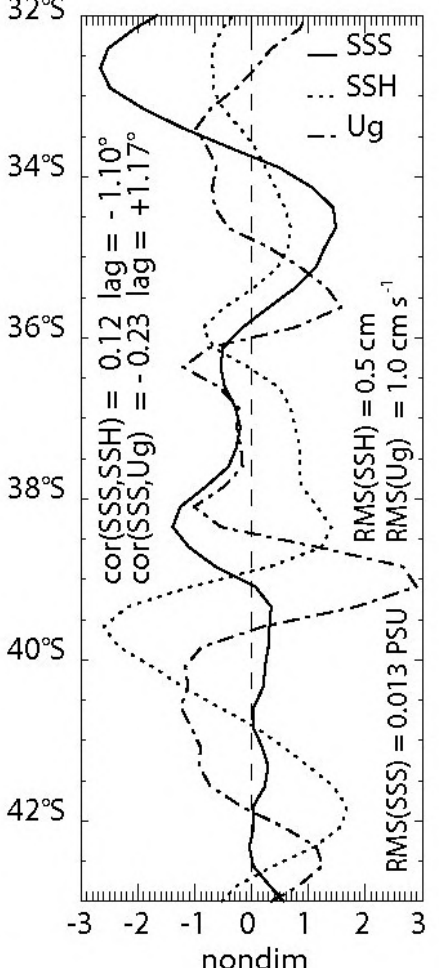

c)

Chl-a

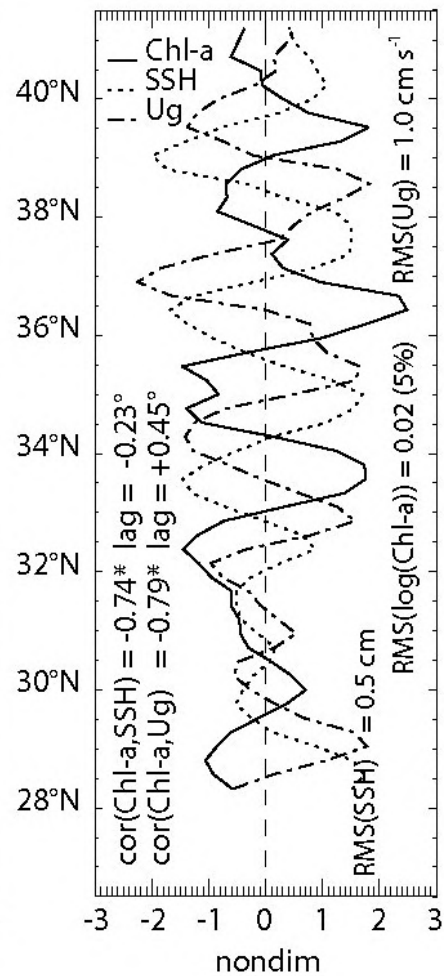

Chl-a$$
\text { f) }
$$

$32^{\circ} \mathrm{S}$

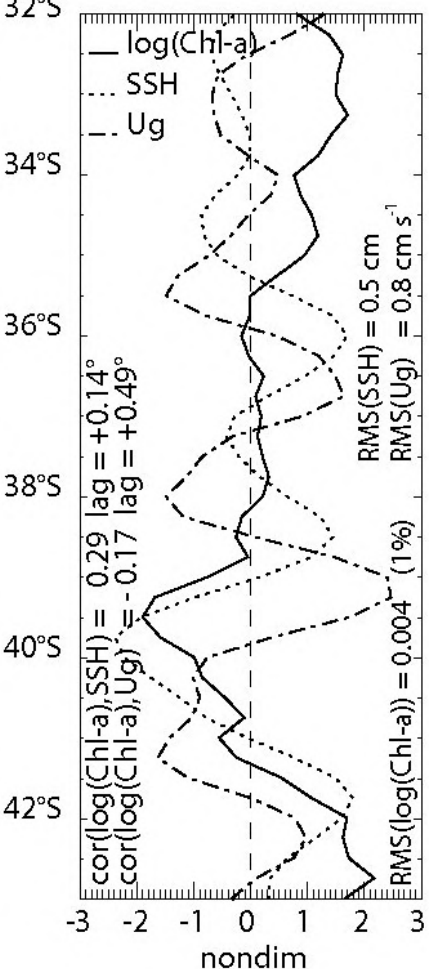

Figure 6. Cross-striation profiles of mean spatially high-pass filtered fields in the (top) ENP and (bottom) ESP, averaged quasi-zonally within the tilted solid boxes on Figures 2 and 3, and normalized by their standard deviation: solid lines are for (left column) AMSR-2 SST, (middle column) SMAP SSS, and (right column) GlobColour log(Chl-a). Dotted and dash-dotted lines on all panels are for SSALTO/DUACS SSH and $\mathrm{U}_{\mathrm{g}}$, respectively. Maximum positive or negative lag-correlations of each tracer profile with both SSH and $\mathrm{U}_{\mathrm{g}}$ are indicated, together with their associated lag (positive lag is when the tracer field is shifted southward). Stars indicate when the correlation is significant at the 5\% level. The standard deviation of each profile before normalization is also indicated, (right column) together with that of the associated Chl-a profile expressed as a fraction of full Chl-a (\%, see Figures 2e and 3e, Appendix A). 


\subsection{ENP Tracer Advection}

In this section, we focus on striation patterns in SST and SSS in the ENP that are consistent with the advection of large-scale water masses by the near-zonal jets, and perform a decomposition of the associated advection terms (Section 2.2). For both tracers and as expected, tilted near-periodic zonally-elongated bands are found in the advection of the large-scale mean tracers by the mesoscale time-mean along-striation currents $-\overline{U_{a H}} \partial \bar{F}_{L} / \partial x_{a} \quad$ (Figures 7a,c). SST advection is stronger near the eastern boundary (Figure 7a), consistently with both swifter mesoscale zonal currents (Figure $2 \mathrm{~g}$ ) and stronger background near-zonal SST gradients associated with coastal upwelling (Figure 2b). SSS advection is highest much further offshore, between $\sim 140^{\circ} \mathrm{W}$ and $\sim 130^{\circ} \mathrm{W}$ and weaker closer to the coast (Figure $7 \mathrm{c}$ ). This is likely the result of the structure of the background SSS gradient oriented mostly in the alongshore direction, which coincides with the cross-striation axis (Figure 2d). For both SST and SSS, the banded structures in $-\overline{U_{a H}} \partial \bar{F}_{L} / \partial x_{a}$ match those in $\overline{F_{H}}$ quite well (white contours on Figures 7a,c).

a)

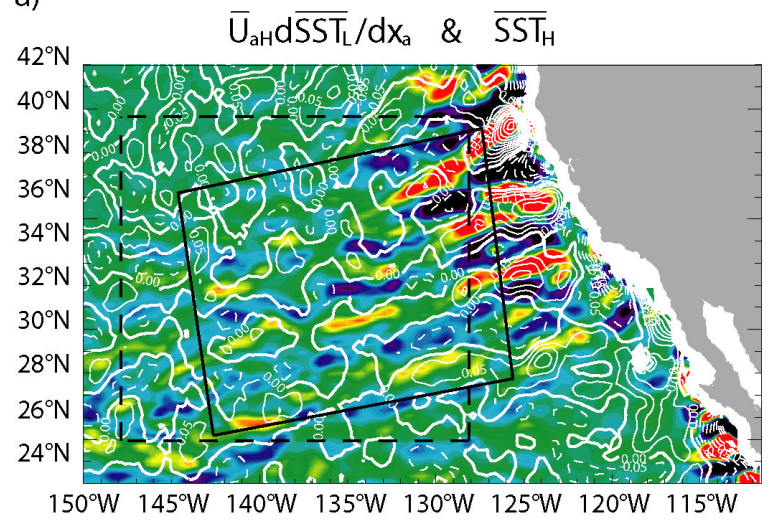

c)

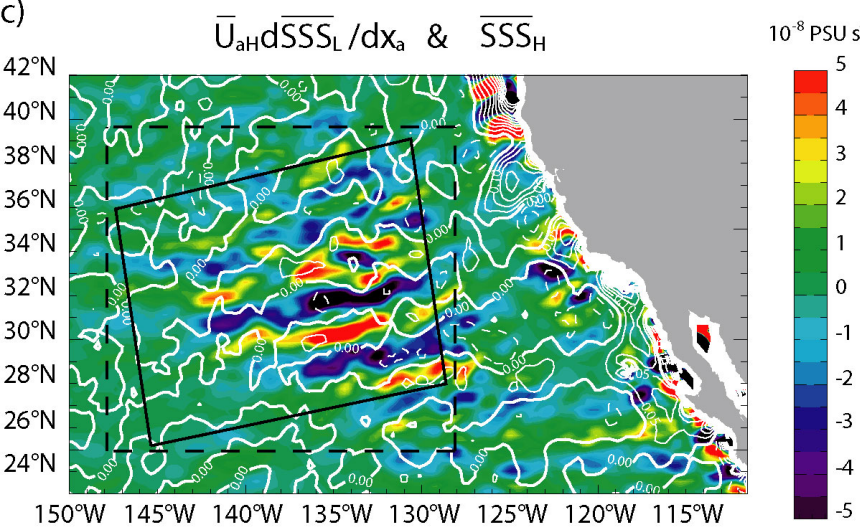

b)
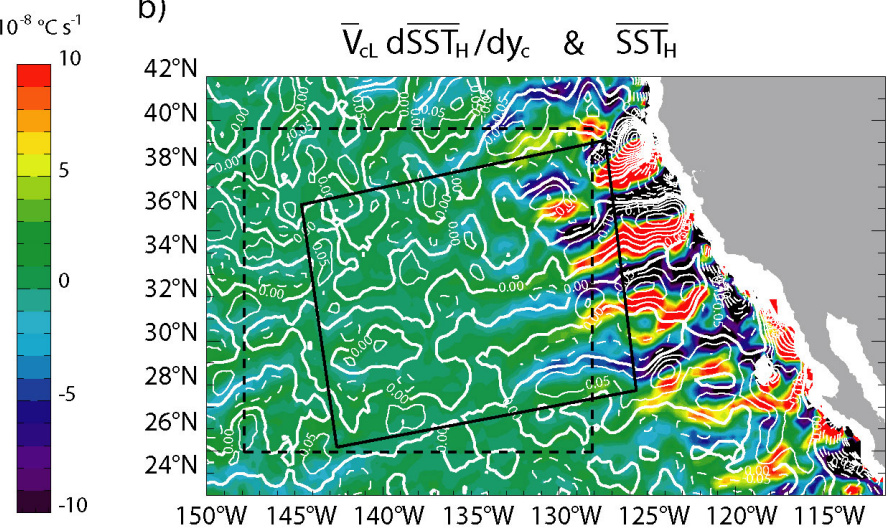

d)

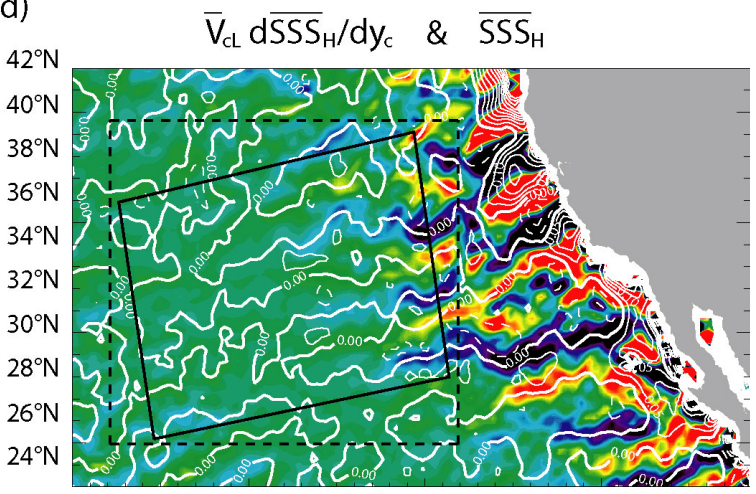

$150^{\circ} \mathrm{W} 145^{\circ} \mathrm{W} 140^{\circ} \mathrm{W} 135^{\circ} \mathrm{W} 130^{\circ} \mathrm{W} 125^{\circ} \mathrm{W} 120^{\circ} \mathrm{W} 115^{\circ} \mathrm{W}$

Figure 7. Advection of (top) SST and (bottom) SSS by striations in the ENP: (a) $-\overline{U_{a H}} \partial \overline{S S T_{L}} / \partial x_{a} ;(\mathbf{b})$ $-\bar{V}_{c L} \partial \overline{S S T_{H}} / \partial y_{c} \quad\left(10^{-8}{ }^{\circ} \mathrm{C} \mathrm{s}^{-1}\right) ;(\mathbf{c})-\bar{U}_{a H} \partial \overline{S S S_{L}} / \partial x_{a} ;(\mathbf{d})-\bar{V}_{c L} \partial \overline{S S S_{H}} / \partial y_{c} \quad\left(10^{-8} \mathrm{PSU} \mathrm{s}^{-1}\right)$. White contours (solid/dashed for positive/negative values) are for (top) $\quad \overline{S S T}_{H} \quad\left(\mathrm{CI}=10^{-2}{ }^{\circ} \mathrm{C}\right)$ and (bottom) $\quad \overline{S S S_{H}}$ $\left(\mathrm{CI}=10^{-2} \mathrm{PSU}\right)$. Solid and dashed boxes as in Figures 2a,c, except that dashed boxes on the top panels are displaced 3 degrees eastward.

Similar bands are also found in the advection of mesoscale mean tracers by the large-scale mean cross-striation flow $-\overline{V_{c L}} \partial \bar{F}_{H} / \partial y_{c}$, except they are located near the continental boundary for both SST and SSS, and weaken sharply west of $\sim 130^{\circ} \mathrm{W}$, though retaining their banded structure through $135-140^{\circ} \mathrm{W}$ (Figures $7 \mathrm{~b}, \mathrm{~d}$ ). This term is banded because its mesoscale structure is defined by the cross-striation tracer gradients (Figures 2a,c). The large-scale surface flow is typical of subtropical 
gyres with equatorward (i.e. cross-striation) currents in the eastern branch and weaker velocities west of $\sim 130^{\circ} \mathrm{W}$ (Figures $1 \mathrm{a}, 2 \mathrm{~h}$ ), thus modulating the intensity of $-\overline{V_{c L}} \partial \overline{F_{H}} / \partial y_{c}$. Unlike the previous term, it appears to be in phase quadrature with the striated mesoscale SST/SSS (white contours on Figures $7 \mathrm{~b}, \mathrm{~d}$ ).

In an attempt to synthesize the information obtained from the sixteen SST and SSS advection terms displayed on Equation (10), Figures 8 and 9 present the corresponding cross-striation profiles, as well as those of mesoscale SST and SSS. The profiles were derived after averaging in the along-striation direction as described earlier, except for the tilted box for SST advection, which was shifted by three degrees eastward to better grasp the $-\overline{V_{c L}} \partial \bar{F}_{H} / \partial y_{c}$ term (Figure $7 \mathrm{~b}$ ). Figures 8 and 9 confirm that the aforementioned two terms are the dominant advection terms. In addition, the eddy terms (advection of mesoscale tracer anomalies by the mesoscale anomalous along-

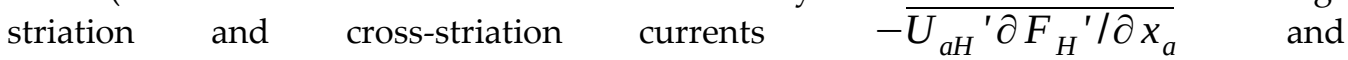
$\left.-\overline{V_{c H}{ }^{\prime} \partial F_{H}{ }^{\prime} / \partial y_{c}}\right)$ also present mesoscale variations along the cross-striation axis, although with no obvious periodicity (Figures $8 \mathrm{~d}, 9 \mathrm{~d}$ ). Importantly, these four mesoscale advection terms are not negligible compared to large-scale advection, especially for SSS (Figures 8a, 9a). Noteworthy, these terms are similar in magnitude for SST, while $-\overline{U_{a H}} \partial \overline{S S S_{L}} / \partial x_{a}$ is 2-3 times higher than other SSS advection terms. Such a result should however be interpreted with caution as it is likely sensitive to the location of the box used to compute cross-striation profiles, due to spatial variations in the intensity of different advection terms (Figure 7).
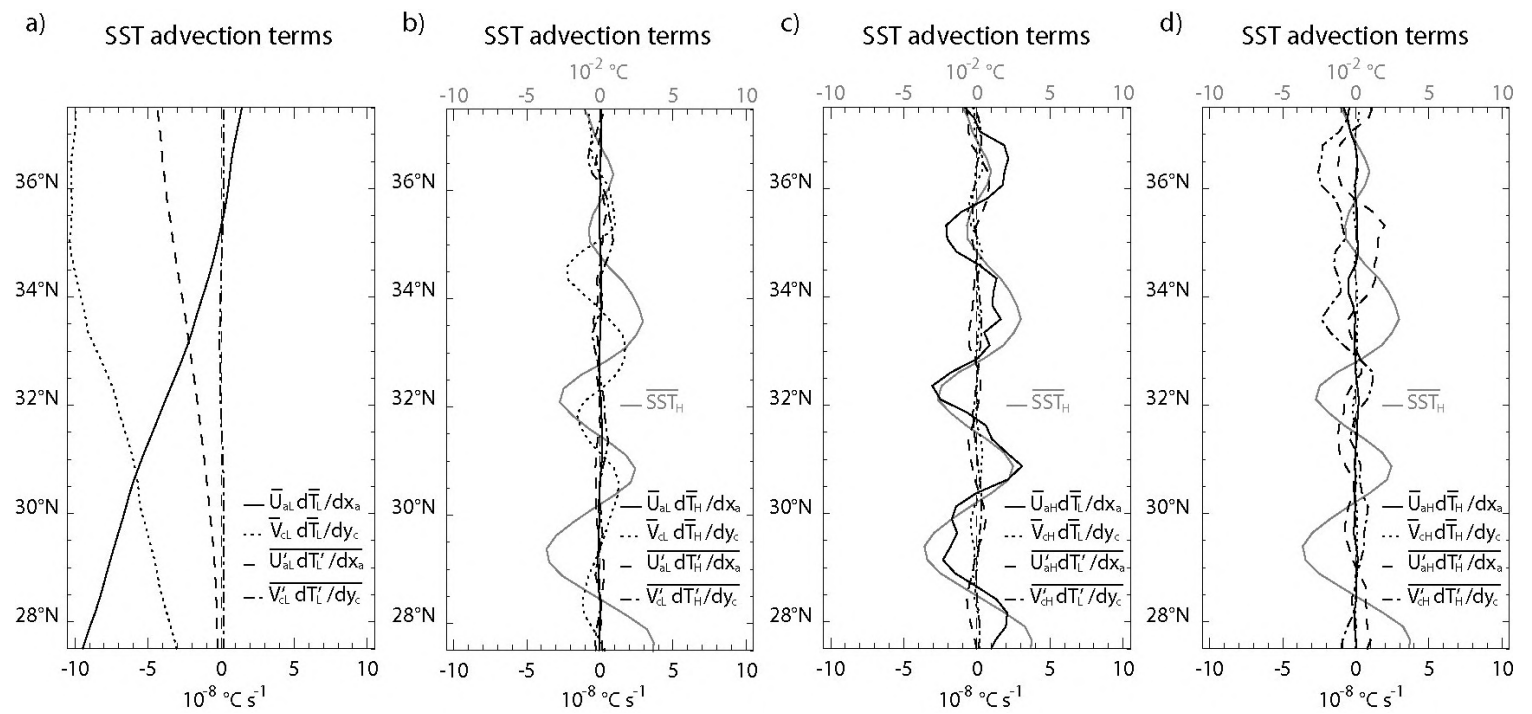

Figure 8. Cross-striation profiles off California of SST advection terms (as listed on equation (10)) averaged quasizonally within the tilted solid box on Figures 7a,b. Each panel displays four terms (mean and eddy along-striation and cross-striation components) accounting for: (a) the advection of large-scale SST by the large-scale flow; (b) the advection of mesoscale SST by the large-scale flow; (c) the advection of large-scale SST by the mesoscale currents; and (d) the advection of mesoscale SST by the mesoscale currents. The profile of mean spatially high-pass filtered SST is also shown on panels $(\mathbf{b}, \mathbf{c}, \mathbf{d})$.

Lag-correlation analysis of profile data confirms (1) the in-phase relationship between mesoscale physical tracers and $-\bar{U}_{a H} \partial \bar{F}_{L} / \partial x_{a}$, with high $(\sim 0.8)$, statistically significant correlations and small lag values $\sim 0.05-0.15^{\circ}$ (Figures $8 \mathrm{c}$ and 9c); and (2) phase quadrature between $\overline{F_{H}}$ and $-\overline{V_{c L}} \partial \overline{F_{H}} / \partial y_{c}$, with significant $\sim 0.8-0.9$ negative correlations at lags $\sim 0.8-0.9^{\circ}$ and advection shifted equatorward (Figures $8 b$ and $9 b$ ). 

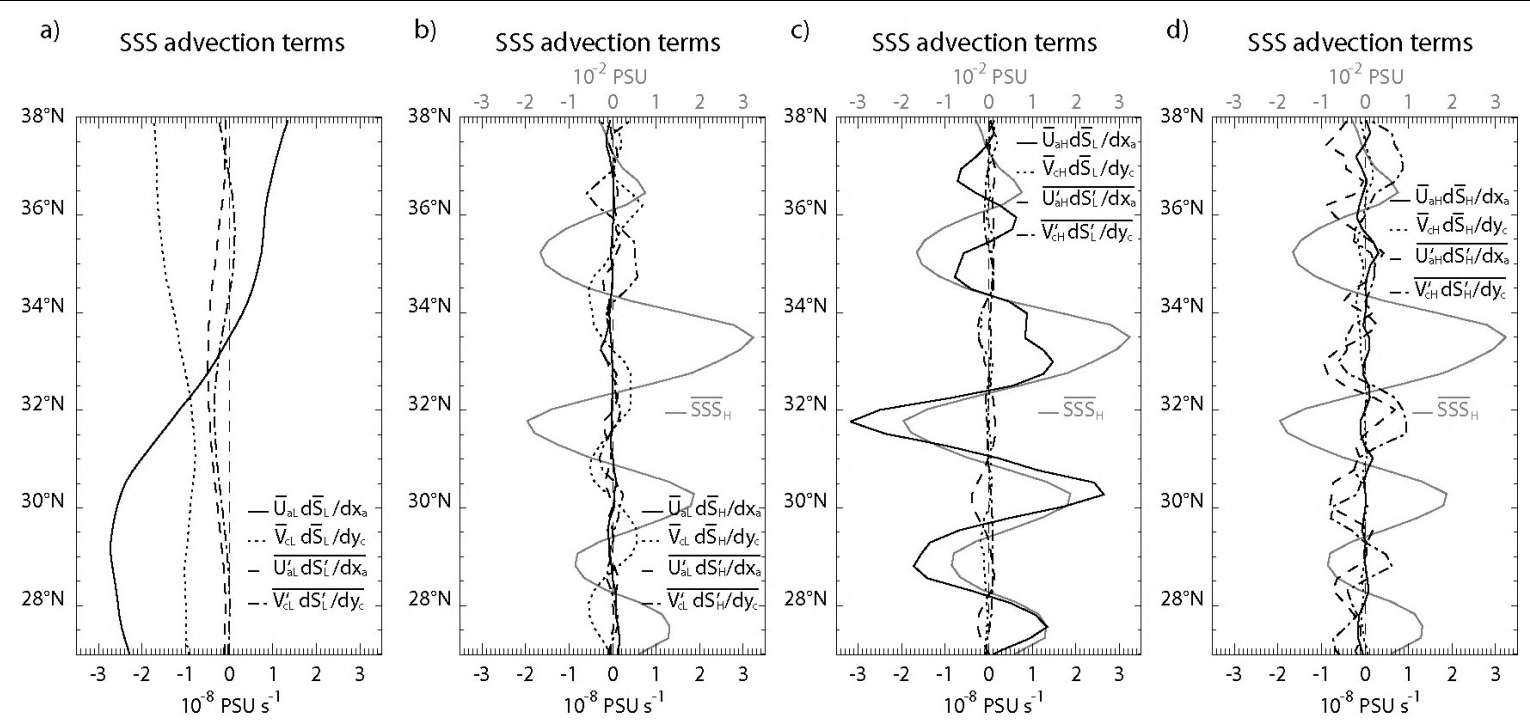

Figure 9. Same as Figure 8, except for SSS advection terms and mean spatially high-pass filtered SSS, averaged quasi-zonally within the tilted solid box on Figures $7 \mathrm{c}, \mathrm{d}$.

\section{Discussion}

The mesoscale SST and SSS budgets depicted above are not closed. Other terms in the tracer balance (Equation (1)) that were not included in this study, such as horizontal/vertical mixing and vertical advection may be important. Future modelling studies at eddy-resolving resolution (typically $0.1^{\circ}$ and higher) and the analysis of extensive in situ data records from e.g. Argo profiling floats [7,45] may help to address this limitation.

In the light of our results, the processes responsible for the generation and persistence of striations in SST and SSS may be conceptualized as follows. Mean quasizonal jets in the ENP advect the large-scale tracer gradients extending between the coast and the subtropical gyre, leading to tracer field deformation (e.g. [23], their Figure 13a). The resulting wavy pattern in the initially near-meridional (i.e. cross-jet) tracer isolines generates near-zonal frontal anomalies that appear as striations in the time-mean mesoscale field. These features are however partly embedded in large-scale equatorward flow typical of subtropical gyres and EBUS. Such current then advects warm/salty anomalies from the north into the tracer front that separates them from a band of cooler/fresher waters to the south, and cool/fresh anomalies into the front delineating a band of warmer/saltier waters. Cross-striation advection does not explain the banded tracer pattern by itself given its shorter near-zonal extent and the phase lag with the tracer field. Other processes such as mixing, vertical advection and horizontal eddy advection likely contribute to the mesoscale SST/SSS patterns as well, allowing to reach equilibrium and maintain striations in SST and SSS.

Unlike striations in SST and SSS, striations in Chl-a appear $\pi$ out of phase with the striated SSH signal in the ENP. Cyclonic mesoscale eddies are thought to contribute to the offshore nutrient and plankton export in EBUS by trapping coastal water during their formation, unlike anticyclonic eddies generated beyond the upwelling front in more oligotrophic environments [46,47]. The observed relationship between the bands in Chl-a and SSH is then consistent with such hypothesis, given that time-mean striations manifest themselves in snapshots as eddy trains [17,25,43]. However, upwelled trapped water is also cooler compared to background open-ocean conditions, which should lead to in-phase SST-SSH relation rather than the phase quadrature evidenced here. Such discrepancy may result from the different locations for the studied physical and biological tracers in the offshore and coastal transition regions, respectively, where different dynamics may be involved. 
To verify this hypothesis, cross-striation profiles of SST and SSS are computed in the same region as Chl-a (tilted box on Figure 2e) and shown on Figure 10. SST is highly $(\sim 0.8)$ and significantly correlated with both SSH and $U_{g}$, with phase lags $\sim-0.5^{\circ}$ and $\sim+0.25^{\circ}$ latitude, respectively. The smaller lag with $U_{g}$ suggests that eddy trapping may not be the dominant driver for striations in SST in this region. Indeed, correlation at zero lag is significant with $U_{g}$ only and higher (0.69) compared to SSH (0.38). Nevertheless, the examination of Figure 10a reveals that SST is more aligned with $\mathrm{U}_{\mathrm{g}}$ north of $\sim 37^{\circ} \mathrm{N}$ and with SSH to the south. These results thus suggest that both eddy trapping and advection probably contribute to the striated tracer patterns in the coastal transition region. Note that SSS is poorly correlated with both $\mathrm{SSH}$ and $\mathrm{U}_{\mathrm{g}}$, and its periodicity is not as marked as for other variables (Figure 10b), which may have to do with the mostly alongshore background SSS gradient (Figure 2d).
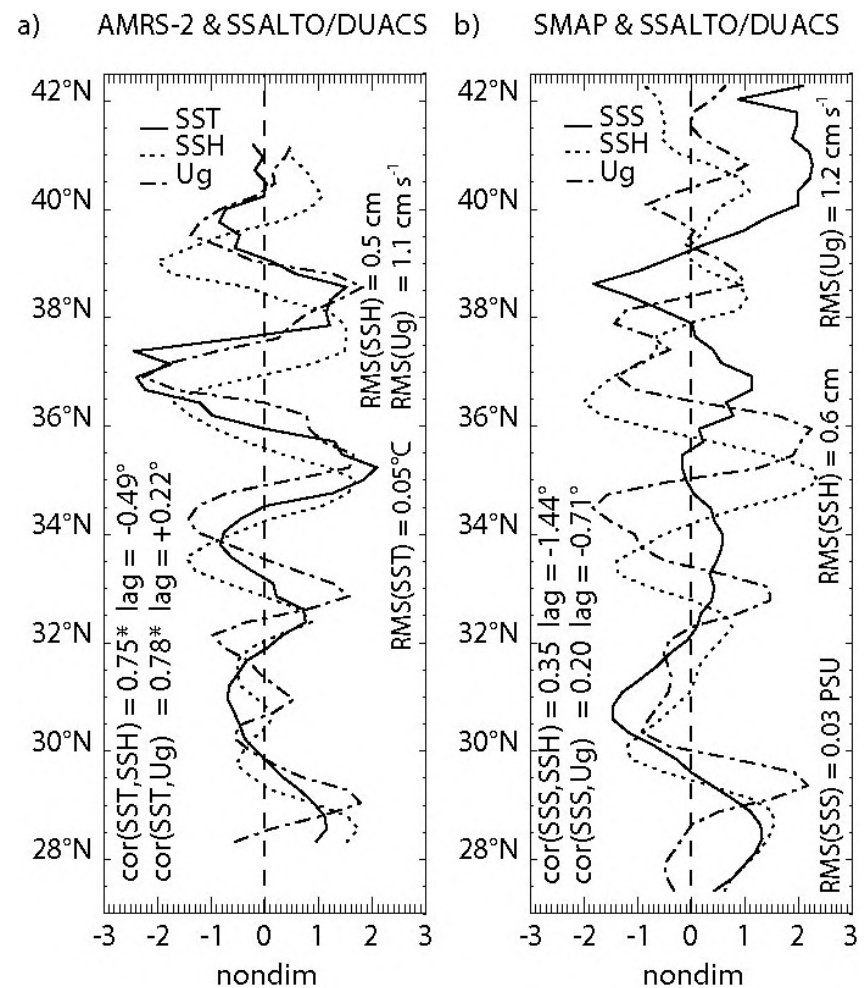

Figure 10. Same as Figures 6a,b, except averaged within the tilted solid box on Figure 2e.

In contrast, striations in the ESP are only evident in the SST field. Phase quadrature between the latter and geostrophic velocity in a region of marked meridional SST gradient suggests a potential role of inhomogeneous isopycnal mixing $[22,23]$.

Except for Chl-a in the ENP, the striated tracer signals reported here are relatively weak (yet significant). Nevertheless, the associated mesoscale meridional SST (SSS) gradients are typically $\pm 10-20 \%( \pm 20-50 \%)$ of the large-scale gradient and locally over $\pm 30 \%$ (near $\pm 100 \%$ ) (Figure 11), implying significant modulation of zonal tracer fronts by striated currents. Besides, instantaneous tracer anomalies associated with eddy trains are likely much stronger than time-mean signals as one might expect from the SST/SSS signatures of mesoscale eddies [25,48]. A composite analysis of those eddies organized in striations may be necessary to extract these transient signals and their contribution to SST/SSS variability in EBUS. 
a)

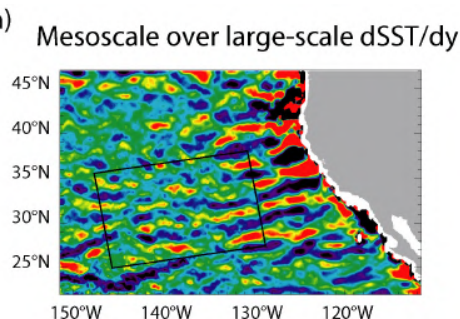

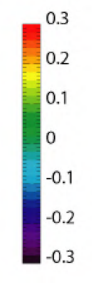

b)

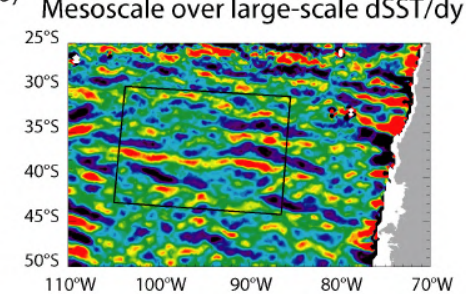

c) Mesoscale over large-scale dSSS/dy

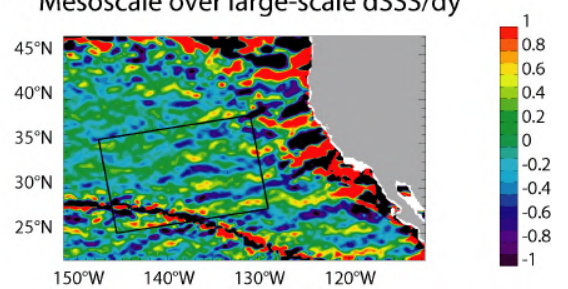

Figure 11. Ratio of spatially high-pass filtered to spatially low-pass filtered time-averaged meridional gradient of $(\mathbf{a}, \mathbf{b})$ AMSR-2 SST and (c) SMAP SSS in the $(\mathbf{a}, \mathbf{c})$ ENP and $(\mathbf{b})$ ESP. The tilted boxes on $(\mathbf{a}, \mathbf{c})$ and $(\mathbf{b})$ are the same as in Figures 2a,c and Figure 3a, respectively.

Despite their similarities, the California and Chile EBUS feature striated patterns of surface tracers with quite distinct characteristics. This is attributed mostly to the location of quasi-zonal jets, either within the large-scale near-zonal tracer gradients and meridional flow (ENP) or much farther west (ESP). These variations among regions and tracers make it difficult to generalize our results to other EBUS regions such as the Benguela and Canary current systems in the Atlantic. Diverse theories for the existence of striated currents [12-23] suggest the possibility of different generation mechanisms in different regions. Combined with the variety of water masses in the global ocean and their spatial properties, particularly the strength and direction of background tracer gradients, such diversity suggests large regional variations in the existence and characteristics of striated tracer fields. Our findings advocate for further research to understand the complex influences of different striations on ocean properties and their variations between different regions.

\section{Conclusions}

Multi-year satellite records from various sensors were used to characterize the effects of striations on SST, SSS, and Chl-a in the subtropical ENP and ESP EBUS. The results vary significantly among the two regions and three surface tracers. In the ENP, while striations in SST and SSS coincide with those in zonal current, suggesting a dominant role of advection, striations in Chl-a are collocated with those in SSH, possibly involving water mass trapping by mesoscale eddy trains. In the ESP, striations were found in SST but neither in SSS nor in Chl-a, except for some meridionallyalternating Chl-a anomalies in the coastal transition zone without clear connections with quasi-zonal jets. Besides, striations in SST are highly correlated with SSH rather than with zonal currents. Unlike the ENP, ESP striations are located far offshore, outside the area of strong background zonal gradients of ocean properties, which explains the weak effects of zonal advection. Therefore, striations probably contribute to coastal/open-ocean exchanges in the ENP, but likely not in the ESP. The decomposition of SST and SSS advection in the ENP into along/cross-striation, mean/eddy, and mesoscale/large-scale parts identifies a dominant contribution from the advection of large-scale mean tracers by the mean quasi-zonal jets, and secondary contributions from the advection of mesoscale mean tracers by the large-scale mean meridional flow and from eddy advection, although mixing and vertical advection likely contribute as well. The persistence of hydrographic striations is thus suggested to result from an interaction between mesoscale (quasi-zonal jets, fronts, and eddies) and large-scale features (tracer gradients and meridional flow). The processes leading to the alignment of the SSH signature of striations with Chl-a in the ENP and SST in the ESP are not confirmed and require future investigation.

Author Contributions: Conceptualization, A.B., P.A., N.M. and S.C.; methodology, A.B., P.A., K.G. and N.M.; software, A.B. and K.G.; validation, A.B.; formal analysis, A.B. and K.G.; investigation, A.B. and P.A.; resources, A.B.; data curation, A.B.; writing-original draft preparation, A.B.; writing-review and editing, A.B., P.A., N.M. and S.C.; visualization, A.B.; supervision, A.B.; project administration, A.B.; funding acquisition, A.B., P.A. and N.M. All authors have read and agreed to the published version of the manuscript. 
Funding: This research was funded by Office of Naval Research Global, grant number N6290916-1-2228. NM is partly supported by the NASA Ocean Surface Topography Science Team through Grant NNX17AH43G and NASA Ocean Salinity Science Team through Grant 80NSSC20K0891. The APC was funded by XXX.

Data Availability Statement: The SSALTO/DUACS altimeter ADT and derived variables were produced and distributed by the Copernicus Climate Change Service (C3S) (https://cds.climate.copernicus.eu/cdsapp\#!/dataset/satellite-sea-level-global?tab=overview). This study has been conducted using E.U. Copernicus Marine Service Information (CMEMS). The GlobCurrent data are available at https://resources.marine.copernicus.eu/? option=com_csw\&view=details\&product_id=MULTIOBS_GLO_PHY_REP_015_004. This study used the SCUD [34] surface velocities provided by APDRC/IPRC. AMSR-2 data are produced by Remote Sensing Systems and were sponsored by the NASA AMSR-E Science Team and the NASA Earth Science MEaSUREs Program. Data are available at www.remss.com/missions/amsr/. The OSTIA data were provided by GHRSST, Met Office and CMEMS. The L3_DEBIAS_LOCEAN_v4 Sea Surface Salinity maps have been produced by LOCEAN/IPSL (UMR CNRS/UPMC/IRD/MNHN) laboratory and ACRI-st company that participate to the Ocean Salinity Expertise Center (CECOS) of Centre Aval de Traitement des Donnees SMOS (CATDS). This product is distributed by the CECOS of the CNES-IFREMER CATDS, at IFREMER, Plouzané (France). Satellite data of sea surface chlorophyll are from the GlobColour product available at https://hermes.acri.fr/.

Conflicts of Interest: The authors declare no conflict of interest. The funders had no role in the design of the study; in the collection, analyses, or interpretation of data; in the writing of the manuscript, or in the decision to publish the results.

\section{Appendix A}

A logarithmic transformation is applied to time-averages of monthly Chl-a data as stated in Section 2.2. Let $\mathrm{A}=\log (\mathrm{Chl}-\mathrm{a})$. A is high-pass filtered as described in Section 2.2. By construction, mesoscale $\mathrm{A}$ is then the difference between $\mathrm{A}$ and large-scale A, which may be viewed as an anomaly relative to the large-scale component:

$$
A_{H}=A-A_{\text {I. }} \text {, }
$$

where $H$ and $L$ subscripts refer to mesoscale and large-scale components, respectively.

For 2-D visualization purposes, it is useful to represent Chl-a expressed in $\mathrm{mg} \mathrm{m}^{-3}$ with a logarithmic color scale (Figures 2f, 3f). This is done by plotting A with a linear color scale, and indicating the associated Chl-a values. For consistency, it is desirable to represent $A_{H}$ in such a way that it may be compared quantitatively with full (unfiltered) Chl-a. Raising 10 to the power of Equation (A1) after moving $A_{L}$ to the left hand side yields:

$$
\text { Chla }=\gamma 10^{A_{L}},
$$

where $\gamma=10^{A_{H}}$. Permutating low-pass filtering and logarithmic transformation does not make much difference on large-scale Chl-a outside a narrow coastal band in both the ENP and ESP (not shown). Therefore:

$$
\text { Chla } \approx \text { YChla }{ }_{\text {I }}
$$

Using scale separation as in (A1) but applied in the original Chl-a space, it can be shown that:

$$
\text { Chla }_{H} \approx \text { Chla }(\gamma-1) / \gamma
$$

The ratio between mesoscale and full Chl-a may thus be approximated with the nondimensional coefficient $(\gamma-1) / \gamma$, which can be readily derived from $\mathrm{A}_{\mathrm{H}}$. A linear color scale is then used for $\mathrm{A}_{\mathrm{H}}$, which we made vary from -0.05 to 0.05 in units of the logarithmic space. The associated $(\gamma-1) / \gamma$ values then range approximately from -0.11 to 0.12 (Figures 2e, 3e).

On the other hand, cross-striation profiles of mesoscale $\log (\mathrm{Chl}-\mathrm{a})$ do not require such inverse transformation because of the normalization by their standard deviation (Figures $6 c, f)$. The latter may be expressed either in units of the logarithmic space (i.e. 
of $\mathrm{A}_{\mathrm{H}}$ ) or as a ratio between mesoscale and full Chl-a (i.e. $(\gamma-1) / \gamma \quad$ ) according to the aforementioned derivation.

\section{Appendix B}

Assuming that nominal errors of satellite sensors are normally distributed, standard error of the mesoscale time-mean SST/SSS fields may be estimated as:

$$
S E_{F_{r}}(x, y)=\sigma_{F_{r}}(x, y) / \sqrt{n},
$$

where $F$ is SST or SSS, subscript $H$ refers to the mesoscale component, $\sigma_{F_{H}}$ is the standard deviation of mesoscale $F$ time series, $n$ is the number of independent observations of mesoscale $F, x$ and $y$ are zonal and meridional coordinates, respectively.

In the regions where hydrographic striations are observed (tilted boxes on Figures $2 \mathrm{a}, \mathrm{c}$ and $3 \mathrm{a}), \quad \sigma_{S S T_{H}}$ is of order $0.25^{\circ} \mathrm{C}$ and $0.35^{\circ} \mathrm{C}$ in the ENP and ESP, respectively, whereas $\sigma_{S_{S S}}$ is of order 0.15 PSU in the ENP (Figure B1). Note that no striated SSS signals were found in the ESP (see Section 3).

On the other hand, striations are associated with the time-averaged signature of westward mesoscale eddy propagation [16,17]. A typical time scale $T$ separating two consecutive independent observations may thus be defined as the time spent by an individual eddy passing through a fixed location. Under the Gaussian eddy approximation, such time corresponds to eddy diameter $D$ divided by eddy zonal translation velocity $c$, which may be estimated from [44] (their Figures 12 and 22). According to their results, $c$ is typically $2 \mathrm{~cm} \mathrm{~s}^{-1}$ in the $30-45^{\circ} \mathrm{S}$ latitude band (ESP) and $2.5 \mathrm{~cm} \mathrm{~s}^{-1}$ in the $25-40^{\circ} \mathrm{N}$ band (ENP), while $D$ is roughly equal to $150 \mathrm{~km}$ in both regions. $T=D / c$ is then $\sim 70$ days and $\sim 90$ days in the ENP and ESP, respectively. Finally, $n$ is obtained by dividing the period of record (2374 days and 1368 days for SST and SSS, respectively) by $T$ and retaining the integer part of the result. This yields 33 and 26 independent SST observations in the ENP and ESP, respectively, and 19 independent SSS observations in the ENP.

a)

Mesoscale SST standard deviation

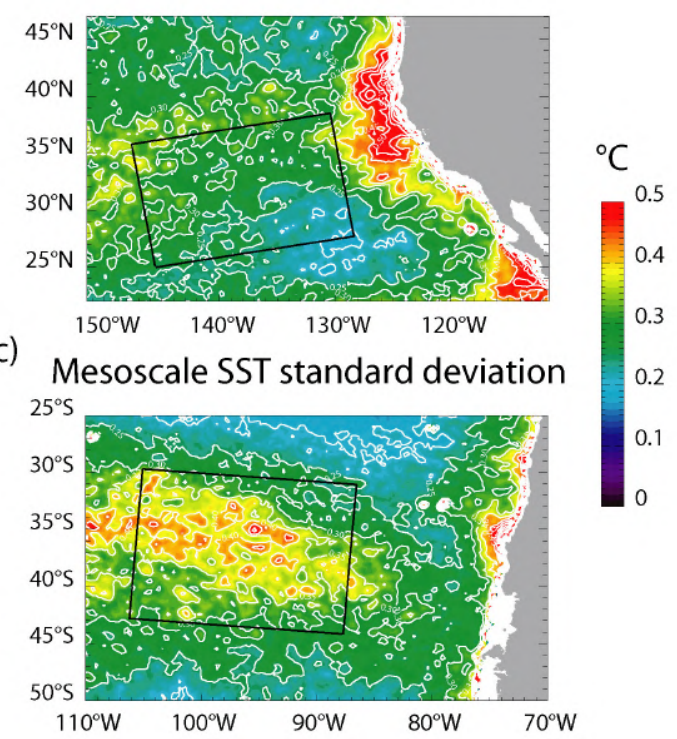

b)
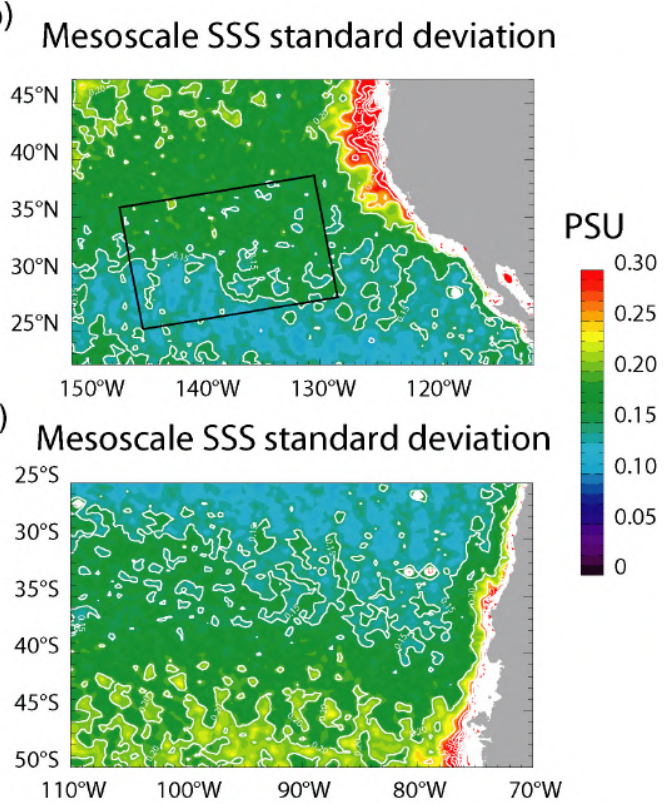

Figure B1. Standard deviation of spatially high-pass filtered $(\mathbf{a}, \mathbf{c})$ AMSR-2 SST $\left({ }^{\circ} \mathrm{C}\right)$ and $(\mathbf{b}, \mathbf{d})$ SMAP SSS (PSU) in the $(\mathbf{a}, \mathbf{b})$ ENP and (c,d) ESP. The tilted boxes on $(\mathbf{a}, \mathbf{b})$ and $(\mathbf{c})$ are as in Figures $2 a, c$ and Figure $3 a$, respectively.

The application of Equation (B1) to the aforementioned estimates of $\sigma_{S S T_{H}}$, $\sigma_{S S S_{H}}$, and $n$ then yields standard errors of $S E_{S S T_{H}} \sim 0.04^{\circ} \mathrm{C}$ and $0.07^{\circ} \mathrm{C}$ in the ENP and ESP, respectively, and $S E_{S S S_{H}} \sim 0.03$ PSU in the ENP. 


\section{References}

1. Chavez, F.P.; Messié, M. A comparison of eastern boundary upwelling ecosystems. Prog. Oceanogr. 2009, 83(1-4), 80-96. doi:10.1016/j.pocean.2009.07.032.

2. Large, W.G.; Danabasoglu, G. Attribution and impacts of upper-ocean biases in CCSM3. J. Clim. 2006, 19, 2325-2346. doi:10.1175/JCLI3740.1

3. Chaigneau, A.; Eldin, G.; Dewitte, B. Eddy activity in the four major upwelling systems from satellite altimetry (1992-2007). Prog. Oceanogr. 2009, 83(1-4), 117-123. doi:10.1016/j.pocean.2009.07.012

4. Chenillat, F.; Franks, P.J.S.; Combes, V. Biogeochemical properties of eddies in the California Current System. Geophys. Res. Lett. 2016, 43, 5812-5820. doi:10.1002/2016GL068945

5. Maximenko, N.A.; Melnichenko, O.V.; Niiler, P.P.; Sasaki, H. Stationary mesoscale jet-like features in the ocean. Geophys. Res. Lett. 2008, 35, L08603. doi:10.1029/2008GL033267

6. Ivanov, L.M.; Collins, C.A.; Margolina, T.M. System of quasi-zonal jets off California revealed from satellite altimetry. Geophys. Res. Lett. 2009, 36, L03609. doi:10.1029/2008GL036327

7. Cravatte, S.; Kestenare, E.; Marin, F.; Dutrieux, P.; Firing, E. Subthermocline and intermediate zonal currents in the tropical pacific ocean: Paths and vertical structure. J. Phys. Oceanogr. 2017, 47(9), 2305-2324.

8. Melnichenko, O.V.; Maximenko, N.A.; Schneider, N.; Sasaki, H. Quasi-stationary striations in basin-scale oceanic circulation: Vorticity balance from observations and eddy-resolving model. Ocean Dyn. 2010, 60, 653-666. doi:10.1007/s10236-009-0260-z.

9. Chen, R.; Flierl, G.R.; Wunsch, C. Quantifying and interpreting striations in a subtropical gyre: A spectral perspective. J. Phys. Oceanogr. 2015, 45, 387-406. doi:10.1175/JPO-D-14-0038.1

10. Zhang, Y.; Guan, Y.P. Striations in marginal seas and the Mediterranean Sea. Geophys. Res. Lett. 2019, 46, $2726-2733$. doi:10.1029/2018GL081050

11. Cornillon, P.C.; Firing, E.; Thompson, A.F.; Ivanov, L.M.; Kamenkovich, I.; Buckingham, C.E.; Afanasyev, Y.D. Oceans. In Zonal jets: Phenomenology, genesis, and physics; Galperin, B., Read, P.L., Eds.; Cambridge University Press: New York, NY, USA, 2019; pp. 46-71.

12. Qiu, B.; Scott, R.B.; Chen, S. Length scales of eddy generation and nonlinear evolution of the seasonally modulated South Pacific Subtropical Countercurrent. J. Phys. Oceanogr. 2008, 38, 1515-1528. doi:10.1175/2007JPO3856.1

13. Schlax, M.G.; Chelton, D.B. The influence of mesoscale eddies on the detection of quasi-zonal jets in the ocean. Geophys. Res. Lett. 2008, 35, L24602. doi:10.1029/2008GL035998

14. Scott, R.B.; Arbic, B.K.; Holland, C.L.; Sen, A.; Qiu, B. Zonal versus meridional velocity variance in satellite observations and realistic and idealized ocean circulation models. Ocean Modell. 2008, 23, 102-112. doi:10.1016/j.ocemod.2008.04.009

15. Wang, J.; Spall, M.A.; Flierl, G.R.; Malanotte-Rizzoli, P. Nonlinear radiating instability of a barotropic eastern boundary current. J. Phys. Oceanogr. 2013, 43, 1439-1452. doi:10.1175/JPO-D-12-0174.1

16. Davis, A.; Di Lorenzo, E.; Luo, H.; Belmadani, A.; Maximenko, N.; Melnichenko, O.; Schneider, N. Mechanisms for the emergence of ocean striations in the North Pacific. Geophys. Res. Lett. 2014, 41, 948-953. doi:10.1002/2013GL057956

17. Belmadani, A.; Concha, E.; Donoso, D.; Chaigneau, A.; Colas, F.; Maximenko, N.; Di Lorenzo, E. Striations and preferred eddy tracks triggered by topographic steering of the background flow in the eastern South Pacific. J. Geophys. Res.: Oceans 2017, 122, 2847-2870. doi:10.1002/2016JC012348

18. Qiu, B.; Chen, S.; Sasaki, H. Generation of the north equatorial undercurrent jets by triad baroclinic Rossby wave interactions. J. Phys. Oceanogr. 2013, 43, 2682-2698. doi:10.1175/jpo-d-13-099.1

19. Xia, Y.; Du, Y.; Qiu, B.; Cheng, X.; Wang, T.; Xie, Q. The characteristics of the mid-depth striations in the North Indian Ocean. Deep-Sea Res. I 2020, 162, 103307. doi:10.1016/j.dsr.2020.103307

20. Delpech, A.; Ménesguen, C.; Morel, Y.; Thomas, L.N.; Marin, F.; Cravatte, S.; Le Gentil, S. Intra-annual Rossby waves destabilization as a potential driver of low-latitude zonal jets: Barotropic dynamics. J. Phys. Oceanogr. 2021, 51(2), 365-384. doi:10.1175/jpo-d-20-0180.1

21. Rhines, P.B. Waves and turbulence on a beta-plane. J. Fluid Mech. 1975, 69, 417-443.

22. Baldwin, M.P.; Rhines, P.B.; Huang, H.-P.; McIntyre, M.E. The jet-stream conundrum. Science $2007,315,467$. doi:10.1126/science.1131375.

23. Delpech, A.; Cravatte, S.; Marin, F.; Morel, Y. Observed tracer fields structuration by middepth zonal jets in the tropical Pacific. J. Phys. Oceanogr. 2020, 50, 281-304. doi:10.1175/JPO-D-19-0132.1

24. Centurioni, L.R.; Ohlmann, J.C.; Niiler, P.P. Permanent meanders in the California Current System. J. Phys. Oceanogr. 2008, 38, 1690-1710. doi:10.1175/2008JPO3746.1

25. Buckingham, C.E.; Cornillon, P.C.; Schloesser, F.; Obenour, K.M. Global observations of quasi-zonal bands in microwave sea surface temperature. J. Geophys. Res.: Oceans 2014, 119, 4840-4866. doi:10.1002/2014JC010088

26. Chen, R.; Flierl, G.R. The contribution of striations to the eddy energy budget and mixing: Diagnostic frameworks and results in a quasigeostrophic barotropic system with mean flow. J. Phys. Oceanogr. 2015, 45, 2095-2113. doi:10.1175/JPO-D14-0199.1

27. Margolskee, A.; Frenzel, H.; Emerson, S.; Deutsch, C. Ventilation pathways for the North Pacific oxygen deficient zone. Glob. Biogeochem. Cyc. 2019, 33, 875-890. doi:10.1029/2018GB006149

28. Pizarro-Koch, M.; Pizarro, O.; Dewitte, B.; Montes, I.; Ramos, M.; Paulmier, A.; Garçon, V. Seasonal variability of the southern tip of the Oxygen Minimum Zone in the eastern South Pacific ( $\left.30^{\circ}-38^{\circ} \mathrm{S}\right)$ : A modeling study. J. Geophys. Res.: Oceans 2019, 124. doi:10.1029/2019JC015201 
29. Maes, C.; Blanke, B.; Martinez, E. Origin and fate of surface drift in the oceanic convergence zones of the eastern Pacific. Geophys. Res. Lett. 2016, 43. doi:10.1002/2016GL068217

30. Taguchi, B.; Furue, R.; Komori, N.; Kuwano-Yoshida, A.; Nonaka, M.; Sasaki, H.; Ohfuchi, W. Deep oceanic zonal jets constrained by fine-scale wind stress curls in the South Pacific Ocean: A high-resolution coupled GCM study. Geophys. Res. Lett. 2012, 39, L08602. doi:10.1029/2012GL051248

31. Dritschel, D.G.; McIntyre, M.E. Multiple jets as PV staircases: The Phillips effect and the resilience of eddy-transport barriers. J. Atmos. Sci. 2008, 65, 855-874. doi:10.1175/2007JAS2227.1

32. Rio, M.-H.; Mulet, S.; Picot, N. Beyond GOCE for the ocean circulation estimate: Synergetic use of altimetry, gravimetry, and in situ data provides new insight into geostrophic and Ekman currents. Geophys. Res. Lett. 2014 , 41. doi:10.1002/2014GL061773

33. Hersbach, H.; et al. The ERA5 global reanalysis. Q. J. R. Meteorol. Soc. 2020. doi:10.1002/qj.3803

34. Maximenko, N.A.; Hafner, J. (2010), SCUD : Surface Currents from Diagnostic model. IPRC Tech. Note 5, 17pp. Available online: http://iprc.soest.hawaii.edu/publications/tech_notes/SCUD_manual_02_17.pdf (accessed on 26 August 2020).

35. Wentz, F.J.; Meissner, T.; Gentemann, C.; Hilburn, K.A.; Scott, J. (2014), Remote Sensing Systems GCOM-W1 AMSR2 Daily Environmental Suite on $0.25 \mathrm{deg}$ grid, Version 8. Remote Sensing Systems, Santa Rosa, CA. Available online: www.remss.com/missions/amsr (accessed on 16 February 2020).

36. Donlon, C.J.; Martin, M.; Stark, J.D.; Roberts-Jones, J.; Fiedler, E.; Wimmer, W. The operational sea surface temperature and sea ice analysis (OSTIA) system. Rem. Sens. Env. 2012, 116, 140-158. doi:10.1016/j.rse.2010.10.017

37. Fore, A.G; Yueh, S.H.; Tang, W.; Stiles, B.W.; Hayashi, A.K. Combined active/passive retrievals of ocean vector wind and sea surface salinity with SMAP. IEEE Trans. Geosci. Rem. Sens. 2016, 54(12), 7396-7404. doi:10.1109/TGRS.2016.2601486

38. JPL (2020), JPL SMAP Level 3 CAP Sea Surface Salinity Standard Mapped Image 8-Day Running Mean V4.3 Validated Dataset. Ver. 4.3. PO.DAAC, CA, USA. Available online: doi:10.5067/SMP43-3TPCS Dataset (accessed on 29 February 2020).

39. Boutin, J.; Vergely, J.L.; Thouvenin-Masson, C.; Supply, A.; Khvorostyanov, D. (2019), SMOS SSS L3 maps generated by CATDS CEC LOCEAN debias V4.0. SEANOE. Available online: doi:10.17882/52804\#69293 (accessed on 12 February 2020).

40. Maritorena, S.; d'Andon, O.H.F.; Mangin, A.; Siegel, D.A. Merged satellite ocean color data products using a bio-optical model: Characteristics, benefits and issues. Rem. Sens. Env. 2010, 114(8), 1791-1804. doi:10.1016/j.rse.2010.04.002

41. Gaube, P.; Chelton, D.B.; Strutton, P.G.; Behrenfeld M.J. Satellite observations of chlorophyll, phytoplanktonbiomass, and Ekman pumping in nonlinear mesoscale eddies. J. Geophys. Res. Oceans 2013, 118, 6349-6370. doi:10.1002/2013JC009027

42. Thompson, R.O.R.Y. Coherence significance levels. J. Atmos. Sci. 1979, 36, 2020-2021.

43. Chen, C.; Kamenkovich, I.; Berloff, P. Eddy trains and striations in quasigeostrophic simulations and the ocean. J. Phys. Oceanogr. 2016, 46, 2807-2825. doi:10.1175/JPO-D-16-0066.1

44. Chelton, D.B.; Schlax, M.G.; Samelson, R.M. Global observations of nonlinear mesoscale eddies. Prog. Oceanogr. 2011, 91, 167216. doi:10.1016/j.pocean.2011.01.002

45. Roemmich, D.; et al. On the future of Argo: A global, full-depth, multi-disciplinary array. Frontiers Mar. Sci. $2019,6$. doi:10.3389/fmars.2019.00439

46. Gaube, P.; McGillicuddy Jr., D.J.; Chelton, D.B.; Behrenfeld, M.J.; Strutton, P.G. Regional variations in the influence of mesoscale eddies on near-surface chlorophyll. J. Geophys. Res.: Oceans 2014, 119, 8195-8220. doi:10.1002/2014JC010111.

47. Nagai, T.; Gruber, N.; Frenzel, H.; Lachkar, Z.; McWilliams, J.C.; Plattner, G.-K. Dominant role of eddies and filaments in the offshore transport of carbon and nutrients in the California Current System. J. Geophys. Res.: Oceans 2015, 120, 5318-5341. doi:10.1002/2015JC010889.

48. Melnichenko, O.; Amores, A.; Maximenko, N.; Hacker, P.; Potemra, J. Signature of mesoscale eddies in satellite sea surface salinity data. J. Geophys. Res.: Oceans 2017, 122, 1416-1424. doi:10.1002/2016JC012420 